\title{
RESEARCH
}

Open Access

\section{Enhancement of tripartite synapses as a potential therapeutic strategy for Alzheimer's disease: a preclinical study in rTg4510 mice}

Joshua B. Foster ${ }^{1}$, Rashelle Lashley ${ }^{1}$, Fangli Zhao ${ }^{1}$, Xueqin Wang ${ }^{1}$, Nydia Kung ${ }^{1}$, Candice C. Askwith ${ }^{1}$, Lin Lin², Michael W. Shultis ${ }^{2}$, Kevin J. Hodgetts ${ }^{2}$ and Chien-Liang Glenn Lin ${ }^{1 *}$ (D)

\begin{abstract}
Background: The lack of effective treatment options for Alzheimer's disease (AD) is of momentous societal concern. Synaptic loss is the hallmark of AD that correlates best with impaired memory and occurs early in the disease process, before the onset of clinical symptoms. We have developed a small-molecule, pyridazine-based series that enhances the structure and function of both the glial processes and the synaptic boutons that form the tripartite synapse. Previously, we have shown that these pyridazine derivatives exhibit profound efficacy in an amyloid precursor protein AD model. Here, we evaluated the efficacy of an advanced compound, LDN/OSU-0215111, in rTg4510 mice — an aggressive tauopathy model.

Methods: rTg4510 mice were treated orally with vehicle or LDN/OSU-0215111 $(10 \mathrm{mg} / \mathrm{kg})$ daily from the early symptomatic stage ( 2 months old) to moderate (4 months old) and severe ( 8 months old) disease stages. At each time point, mice were subjected to a battery of behavioral tests to assess the activity levels and cognition. Also, tissue collections were performed on a subset of mice to analyze the tripartite synaptic changes, neurodegeneration, gliosis, and tau phosphorylation as assessed by immunohistochemistry and Western blotting. At 8 months of age, a subset of rTg4510 mice treated with compound was switched to vehicle treatment and analyzed behaviorally and biochemically 30 days after treatment cessation.
\end{abstract}

Results: At both the moderate and severe disease stages, compound treatment normalized cognition and behavior as well as reduced synaptic loss, neurodegeneration, tau hyperphosporylation, and neuroinflammation. Importantly, after 30 days of treatment cessation, the benefits of compound treatment were sustained, indicating disease modification. We also found that compound treatment rapidly and robustly reduced tau hyperphosphorylation/deposition possibly via the inhibition of GSK3 $\beta$.

Conclusions: The results show that LDN/OSU-0215111 provides benefits for multiple aspects of tauopathy-dependent pathology found in Alzheimer's disease including tripartite synapse normalization and reduction of toxic tau burden, which, in turn, likely accounted for normalized cognition and activity levels in compound-treated rTg4510 mice. This study, in combination with our previous work regarding the benefit of pyridazine derivatives against amyloiddependent pathology, strongly supports pyridazine derivatives as a viable, clinically relevant, and disease-modifying treatment for many of the facets of Alzheimer's disease.

Keywords: Alzheimer's disease, Glutamate transporter EAAT2, Tauopathy, Small-molecule, rTg4510

\footnotetext{
*Correspondence: lin.492@osu.edu

'Department of Neuroscience, College of Medicine, The Ohio State

University, Columbus, OH, USA

Full list of author information is available at the end of the article
}

(c) The Author(s). 2019 Open Access This article is distributed under the terms of the Creative Commons Attribution 4.0 International License (http://creativecommons.org/licenses/by/4.0/), which permits unrestricted use, distribution, and reproduction in any medium, provided you give appropriate credit to the original author(s) and the source, provide a link to the Creative Commons license, and indicate if changes were made. The Creative Commons Public Domain Dedication waiver (http://creativecommons.org/publicdomain/zero/1.0/) applies to the data made available in this article, unless otherwise stated. 


\section{Background}

Alzheimer's disease (AD) is a devastating, progressive neurodegenerative disease that affects approximately 50 million people worldwide and still lacks effective therapeutic options $[1,2]$. Current clinical therapies (i.e., cholinesterase inhibitors and $N$-methyl-D-aspartate (NMDA) receptor antagonists) only modestly slow the disease progression [3-5]. AD is characterized by the extracellular deposition of the amyloid $\beta$ proteins in the form of plaques and the intracellular aggregation of tau proteins in the form of filaments [6-8]. Therapeutic approaches have been developed to enhance brain clearance of accumulated amyloid $\beta$ and aberrant tau aggregation [9-13]; however, these approaches have not yet demonstrated success in humans. There is an imminent need to develop novel therapeutics for $\mathrm{AD}$.

Glutamatergic neurons, located in the frontal, temporal (especially the hippocampus), and parietal cortices, are severely affected in $\mathrm{AD}$ patients $[14,15]$. Studies in $\mathrm{AD}$ brains indicate that cognitive deficits are more highly correlated with loss of glutamatergic synapses than with neurofibrillary tangles or amyloid $\beta$ burden [16-18]. Several components of the glutamate cycle, including reduced glutamate uptake activity, are disrupted in AD and are associated with cognitive decline [19-22]. Multiple lines of evidence indicate that glutamate-mediated hyperactivity of the memory network, particularly the hippocampal regions, precedes AD pathology. For example, elevated hippocampal activation was observed in individuals at risk for $\mathrm{AD}$, including carriers of ApoE4, carriers of genetic mutations in familial $\mathrm{AD}$, and patients with mild cognitive impairment [23-27]. In addition, seizures and epileptiform activity were found to be associated with the onset of cognitive decline and precede or coincide with the diagnosis of mild cognitive impairment or AD $[19,28]$. Preventing excess glutamate-mediated toxicity and hyperexcitability is a potential therapeutic target.

Excitatory amino acid transporter 2 (EAAT2) is primarily localized in perisynaptic processes of astrocytes, closely associated with excitatory synaptic contacts [29]. EAAT2 plays a critical role in the maintenance of low extracellular glutamate levels [30, 31]. EAAT2 also plays an essential role in cognitive memory functions [32-34]. Notably, loss of EAAT2 protein and function is commonly found in $\mathrm{AD}$ patients and is an early event in disease pathology $[19,35,36]$. To determine whether the loss of EAAT2 contributes to AD, Mookherjee et al. crossed mice lacking one allele for EAAT2 with A $\beta$ PPswe/PS1 $\triangle E 9$ mice and found that the crossed mice exhibited accelerated cognitive deficits [37]. In addition, we previously crossed EAAT2 transgenic mice, which express 1.5-2-folds more EAAT2, with $\mathrm{APP}_{\mathrm{Sw}, \text { Ind }}$ mice [38]. The crossed mice, which had normal EAAT2 protein levels and function, exhibited significantly reduced spontaneous seizure-mediated premature death, improved cognitive functions, restored synaptic integrity, and reduced amyloid deposition, compared with their APP littermates. These studies suggest that enhanced EAAT2 function is a potential therapeutic strategy for $\mathrm{AD}$.

Expression of EAAT2 protein is highly regulated at the translational level, and this translational control mechanism plays a critical role in the regulation of synaptic activity [33, 39, 40]. We previously executed high-throughput screening to search for compounds that increase EAAT2 expression through translational activation [41]. A pyridazine-based lead series was identified [42]. Studies on the mechanism of action reveal that pyridazine derivatives activate local translation of a subset of transcripts, including EAAT2, in perisynaptic astrocytic processes (PAP). This results in rapidly upregulating a subset of PAP proteins and enhancing the plasticity of the PAP $[41,43]$. Importantly, enhanced plasticity of PAP subsequently leads to increased synaptic protein expression in the synapse and strengthened synaptic long-term potentiation (LTP) $[41,43]$. Thus, pyridazine derivatives are capable of enhancing the structural and functional plasticity of tripartite synapses.

We previously assessed the efficacy of a compound, LDN/ OSU-0212320, from the series in $\mathrm{APP}_{\mathrm{Sw}, \text { Ind }}$ mice [38]. We found that this compound normalized EAAT2 expression and provided profound efficacy by preventing the development of progressive disease pathology and reversing preexisting behavioral, synaptic, and biochemical pathologies. To further develop this compound series towards a clinical application for $\mathrm{AD}$, we assessed the efficacy of an advanced compound, LDN/OSU-0215111, in rTg4510 mice-a mouse model that exhibits tau-mediated AD-like pathology. rTg4510 mice harbor the familial MAPT*P301L mutation $[44,45]$. Previous reports indicate that rTg4510 mice, like APP models, exhibit increased glutamate release, decreased glutamate clearance, and hyperexcitability in the hippocampus before neuron loss or tangle deposition [46]. Here, we report the findings of this efficacy study. We found that LDN/ OSU-0215111 treatment in rTg4510 mice almost completely normalized pathological phenotypes at the moderate disease stage and continued to provide protection at the severe disease stage. The benefits were sustained 1 month after treatment cessation, indicating disease modification. We also found that compound treatment directly reduced toxic forms of mutant phosphorylated tau (pTau) and deposition through inhibition of the tau kinase glycogen synthase kinase-3 beta (GSK3 $\beta)$. The current study, in combination with our previous work, suggests that pyridazine derivatives have potential in the treatment of $\mathrm{AD}$.

\section{Methods}

\section{Animals}

In all experiments, we utilized rTg4510 mice (Jackson; Stock \#024854). MAPT*P301L expression requires the presence of two transgenes $[45,47]$. The mouse prion 
protein promoter mediates the expression of the four-repeat microtubule-associated form of tau harboring the P301L mutation associated with familial frontal temporal dementia with Parkinsonism-17. The MAPT*P301L transgene expression is further regulated by a tetracycline-responsive element upstream of the mouse prion promoter, and therefore, its expression can be controlled in a temporal and cell type-specific manner. Transgenic expression of the tetracycline-controlled transactivator protein (tTA) is necessary to allow transcription of MAPT*P301L. The expression of tTA is effectively limited to neurons in the forebrain as it is regulated by the CamKII promoter. Doxycycline (DOX) can be used to substantially reduce mutant tau expression. However, we chose not to treat mice with DOX. Control mice were either non-transgenic or only expressed the tTA transgene, to avoid any potential leakiness of the MAPT*P301L transgene. Mice were housed in a 12-h light/dark cycle with access to food and water ad libitum except in two circumstances where mice were partially food deprived. During deprivation, mice were given sufficient food to maintain $85 \%$ of their body weight. Food deprivation occurred (1) during a 2-day period prior to the start of compound treatment to train the mice to consume honey emulsion and (2) during the T-maze task. Mice were sacrificed, and the forebrain, hippocampus, and prefrontal cortex of mice were collected and processed as described. All experiments were approved by the Institutional Animal Care and Use Committee of The Ohio State University and the National Institutes of Health Guide for the Care and Use of Laboratory Animals.

\section{Study design}

Initially, a cohort of rTg4510 mice were crossed to EAAT2 overexpression mice [48] to determine if EAAT2 overexpression alone modulated disease state. At 4 months of age, rTg4510 $\times$ EAAT2 mice were submitted to behavioral testing and the brains were collected for pathology analysis. For the compound study, rTg4510 mice were treated daily with vehicle or LDN/OSU-0215111 (10 mg/kg) from the early symptomatic stage ( 2 months old) to moderate (4 months old) and severe ( 8 months old) disease stages. At 8 months of age, a subset of $\mathrm{rTg} 4510$ mice treated with the compound was switched to vehicle treatment and analyzed behaviorally and biochemically 30 days later. At each time point for each cohort, all mice were subjected to a battery of behavioral tests to assess the activity levels and cognition. Concurrently at each time point, a subset of mice was sacrificed and the brains were collected and processed as described to analyze the tripartite synaptic changes, neurodegeneration, gliosis, and tau phosphorylation as assessed by immunohistochemistry and Western blotting.

\section{Drugs/compounds}

The present study was completed utilizing an advanced compound, LDN/OSU-0215111, derived from a pyridazine structure. We previously performed efficacy studies and a structure-activity relationship study on an earlier, tool pyridazine compound [42, 49]. The current compound was soluble in water unlike earlier compounds that were only soluble in DMSO. LDN/OSU-0215111 was dissolved in water, warmed to $37^{\circ} \mathrm{C}$ for $5 \mathrm{~min}$, and mixed with pre-warmed $1 \%$ polyethylene glycol 400 (Sigma-Aldrich) and 0.2\% Tween-80 (Sigma-Aldrich). Vehicle was prepared in the same manner without compound. Vehicle and compound mixtures were then emulsified in warm $50 \%$ honey and $10 \%$ hydroxypropyl$\beta$-cyclodextrin (Sigma-Aldrich) in $\mathrm{dd}_{2} \mathrm{O}$. Compound or vehicle was administered daily at $10 \mathrm{mg} / \mathrm{kg}$ as a single oral dose via pipette based on individual body weight (measured once per week).

\section{Doxycycline treatment}

To assess if mutant tau expression correlates with increased EAAT2 observed in the present study, a cohort of mice were treated with doxycycline (DOX). rTg4510 mice were produced as described above. At 2 months old, a cohort of rTg4510 mice was switched from standard chow to DOX chow (Bio-Serv doxycycline grainbased rodent diet, $200 \mathrm{mg} / \mathrm{kg}$ ) similar to a previously described protocol [50]. Mice were allowed to freely access DOX chow until the end of the study 3 weeks later. A cohort of littermates (control and rTg4510) remained on normal rodent chow for comparison. Tissues were collected, processed, and analyzed as described.

\section{Gliosome/synaptosome isolation}

To assess protein content of perisynaptic astrocytic processes and synaptic boutons of neurons, one hemisphere of the mouse forebrain was subjected to a gliosome preparation. The procedure was performed as previously described [43]. Gliosome and synaptosome fractions were collected after the last cleanup spin and re-suspended in $1 \times$ PBS with $1 \times$ protease inhibitor (Pierce). Relative protein expression of EAAT2 was analyzed using Western blotting.

\section{Postsynaptic density isolation}

Hippocampal postsynaptic densities were isolated as previously described $[51,52]$. Briefly, one hippocampus was dissected, homogenized for 30 strokes in $500 \mu \mathrm{L}$ of homogenization buffer, and passed through a 26-gauge needle ten times. A sample of total cell lysate was collected. The remaining total lysate was spun at $1000 \times g$ for $10 \mathrm{~min}$, and the supernatant (S1) was collected. S1 protein concentration was assessed by Bradford protein 
assay. An equal amount of S1 protein was loaded, and the total volume was normalized between samples with homogenization buffer. Samples were spun at $10,000 \times g$ for $15 \mathrm{~min}$ followed by the removal of supernatant and resuspension of P2 in $100 \mu \mathrm{L}$ homogenization buffer. Ten percent of P2 was collected (crude membrane fraction) to assess the region-specific expression of EAAT2. The remaining P2 was incubated on ice in $1.4 \mathrm{~mL}$ of extraction buffer (containing 0.5\% Triton X-100). Samples were then centrifuged in a Beckman L8-55 M ultracentrifuge (SW $60 \mathrm{Ti}$ swinging-bucket rotor) at 32,000 $\times \mathrm{g}$ for $20 \mathrm{~min}$. The S3 supernatant was removed and collected, and the P3 pellet (postsynaptic densities) was resuspended in $100 \mu \mathrm{L}$ of TE buffer containing $1 \times$ protease and phosphotase inhibitor (Pierce). Samples were analyzed by Western blot by loading the same volume for each sample.

\section{Sarkosyl extraction}

Sarkosyl-insoluble proteins were isolated as previously described [53]. Briefly, one hemisphere was collected and weighed. The tissue was homogenized with 10 strokes of a pestle in $10 \times$ volume of the brain weight. Samples were spun at $27,000 \times g$ for $20 \mathrm{~min}$. The S1 supernatant was removed, and the P1 pellet was resuspended in $5 \times$ volumes (of the original brain weight) of high salt/sucrose buffer. Samples were spun at 27,000 $\times g$ for $20 \mathrm{~min}$. The S2 supernatant was collected, $150 \mu \mathrm{L}$ of $10 \%$ Sarkosyl was added, and the volume was normalized to $1.5 \mathrm{~mL}$. Samples were then incubated at $37^{\circ} \mathrm{C}$ for 60 min. Samples were spun at $150,000 \times g$ for $60 \mathrm{~min}$. The S3 supernatant was collected, and the P3 pellet was resuspended in one-half volume (of the original brain weight) of TE buffer containing $1 \times$ protease and phosphotase inhibitor (Pierce). The preparation yielded P3 fractions that were composed almost exclusively of 64$\mathrm{kDa}$ tau species. Samples were analyzed by Western blot by loading the same volume for each sample.

\section{Hippocampal extracellular biotinylation}

Hippocampal biotinylation was performed exactly as previously described [43]. Briefly, the hippocampi from deeply anesthetized mice were dissected and sliced into 400- $\mu \mathrm{M}$-thick sections (Mcllwain tissue chopper). The hippocampal sections were washed three times in $1 \times$ PBS before being incubated with Ez-link Sulfo-LC-LCbiotin $(1 \mathrm{mg} / \mathrm{mL}$, Thermo Fisher), a cell impermeable biotinylation reagent, for $30 \mathrm{~min}$. To quench the reaction, biotinylation reagent was removed and the samples were washed in $1 \times$ PBS, followed by $100 \mathrm{mM}$ glycine, and again with $1 \times$ PBS. Plasma membrane proteins were liberated by incubation with radioimmunoprecipitation assay buffer. Subsequently, $100 \mathrm{mg}$ of protein was incubated with $25 \mu \mathrm{L}$ of Neutravidin beads (Pierce) overnight at $4{ }^{\circ} \mathrm{C}$. Beads were collected by centrifugation and washed three times in $1 \times$ PBS. Beads were resuspended in $40 \mu \mathrm{L}$ of $2 \times$ SDS loading buffer and heated at $95^{\circ} \mathrm{C}$ for $10 \mathrm{~min}$ to release the protein bound to the beads. An equal volume of each sample was analyzed by Western blot analysis.

\section{Lipid-raft microdomain isolation}

Lipid-raft microdomain isolation was performed exactly as previously described [43]. Briefly, mice were euthanized and one hemisphere of the forebrain was homogenized by 30 strokes in a class B Dounce homogenizer in $2 \mathrm{~mL}$ of homogenization buffer $(150 \mathrm{mM} \mathrm{NaCl}, 25 \mathrm{mM}$ MES, and $1 \times$ protease inhibitor, $\mathrm{pH}$ 6.5). After five passages through a 26-gauage needle, the homogenate was centrifuged at $1000 \times g$ for $10 \mathrm{~min}$ to remove cell bodies. An equal amount of protein from the resultant supernatant was then incubated with Brij-58 (1\% final volume) at $4{ }^{\circ} \mathrm{C}$ for $1 \mathrm{~h}$. Sucrose ( $40 \%$ final concentration by volume) was then added to the sample. One milliliter of the sample was loaded into an ultracentrifuge tube (Beckman) and overlaid with $1.8 \mathrm{~mL}$ of $30 \%$ sucrose and 1.2 $\mathrm{mL}$ of $5 \%$ sucrose (both resuspended in homogenization buffer). The gradients were centrifuged overnight (16 h) at $4{ }^{\circ} \mathrm{C}$ at $175,587 \times g$. A total of 10 fractions $(400 \mu \mathrm{L} /$ fraction) were isolated using a pipette starting from the top, and the pellet (fraction 11) was resuspended in $400 \mu \mathrm{L}$ of homogenization buffer. Protein readings were analyzed for each fraction. For Western blot analysis, the same amount of protein was loaded into each lane. The lipid raft marker flotillin-1 was used to identify the fractions that represent the lipid raft microdomain.

\section{Western blotting}

Western blotting was performed as previously described [43]. Protein concentrations were determined by modified BradfordLowry (DC Protein Assay, Bio-Rad). Briefly, samples were loaded onto $8 \%$ SDS-PAGE polyacrylamide gels for separation. Proteins were transferred (Trans-Blot Trubo, Bio-Rad) to nitrocellulose membranes for antibody probing. The membranes were blocked in $5 \%$ non-fat dried milk in Tris-buffered saline with Tween-20 (0.1\%) (TBS-T) for $30 \mathrm{~min}$. After washing in TBS-T, the membranes were incubated with primary antibodies overnight, with gentle rocking, at $4{ }^{\circ} \mathrm{C}$. The primary antibodies used in the current study include the following: EAAT2 (custom antibody, see [48]), PSD-95 (Thermo Scientific, AB 20923961), NMDAR2B (Millipore, AB_90772), synaptophysin (Cell Signaling Technology, AB_1904154), Tau5 (Invitrogen, AB_2536235), Tau-AT8 (Thermo Fisher, AB_223647), TauPHF1 (gift of Dr. Peter Davies, AB_2315150), Tau-MC1 (gift of Dr. Peter Davies, AB_2314773), GSK3 3 (Santa Cruz Biotechnology, AB_1123754), pGSK3ß-ser9 (Santa Cruz Biotechnology, AB_10920410), flotillin-1 (Cell Signaling Technology, catalog\# 1863S), and GAPDH (Santa Cruz Biotechnology, AB_ 
10847862). After washing in TBS-T, the membranes were incubated in the respective secondary antibody for $1 \mathrm{~h}$. The membranes were again washed in TBS-T and incubated with WesternBright (Advansta) enhanced chemiluminescence substrate according to the manufacturer's instructions. Digital images were acquired using the ChemiDoc Imaging System (Bio-Rad). Signal intensities were analyzed for each antibody. The intensity for proteins of interest was normalized by the loading control flotillin-1 or GAPDH intensity to account for loading variability, when appropriate. Semi-quantitative protein expression was calculated as fold change relative to the control(s) for each blot.

\section{Long-term potentiation}

Recordings for LTP were performed exactly as previously described [43]. Briefly, the brains were dissected and held in ice-cold cutting solution (250 mM sucrose, $25 \mathrm{mM}$ D-glucose, $2.5 \mathrm{mM} \mathrm{KCl}, 24 \mathrm{mM} \mathrm{NaHCO} 3,1.25$ $\mathrm{mM} \mathrm{NaH}{ }_{2} \mathrm{PO}_{4}, 2.0 \mathrm{nM} \mathrm{CaCl}, 1.5 \mathrm{mM} \mathrm{MgSO}_{4}$, and 1.0 $\mathrm{mM}$ kynurenic acid ( $\mathrm{pH}$ 7.3-7.4). A vibratome (Leica) was used to collect coronal hippocampal slices $(400 \mu \mathrm{m})$. The sections were maintained in a perfusion chamber filled with artificial cerebral spinal fluid $(124 \mathrm{mM} \mathrm{NaCl}$, $3 \mathrm{mM} \mathrm{KCl}, 24 \mathrm{NaHCO}_{3}, 1.25 \mathrm{mM} \mathrm{NaH} \mathrm{PO}_{4}, 2.0 \mathrm{mM}$ $\mathrm{CaCl}_{2}, 1.0 \mathrm{mM} \mathrm{MgSO}$, and $10 \mathrm{mM}$ D-glucose 10, bubbled with $95 \% \mathrm{O}_{2}$ and $5 \% \mathrm{CO}_{2}, \mathrm{pH}$ 7.3-7.4), for recovery for $1 \mathrm{~h}$. Local field excitatory postsynaptic potentials from the stratum radiatum of CA1 were recorded after stimulation (100 $\mu$ s duration, every $20 \mathrm{~s}$ ) of the Schaffer collaterals. Input-output curves were generated for each slice to identify the stimulation intensity that evoked $50 \%$ the maximum response (approximately 0.2-0.3 $\mathrm{mA}$ ). Theta-burst stimulation (TBS) was used to induce LTP. Each LTP experiment began with baseline recording for $5 \mathrm{~min}$, followed by TBS, and recording LTP for $30 \mathrm{~min}$. The evoked peak fEPSP was measured and normalized relative to the 5 -min averaged baseline. Data were analyzed using Clampex 10.6 software.

\section{Immunohistochemistry}

Immunohistochemistry (IHC) was performed as previously described [54]. The paraformaldehyde-fixed, sucrose-cryoprotected hemispheres were cut at $30 \mu \mathrm{m}$, in the sagittal plane, on a sliding, freezing microtome (Leica SM2010R). The free-floating sections were blocked in $1 \times$ PBS, $0.2 \%$ Triton X-100, and 5\% normal goat serum for $60 \mathrm{~min}$. Next, the sections were incubated in primary antibody overnight at $4{ }^{\circ} \mathrm{C}$. Primary antibodies used include the following: NeuN (Millipore, AB_2298772, 1:100), GFAP (Sigma-Aldrich, AB_477010, 1:1000), synaptophysin (Cell Signaling Technology, AB_1904154, 1:100), TauMC1 (gift of Dr. Peter Davies, AB-2314773, 1:100), and Iba1 (GeneTex, AB_1240343, 1:100). The sections were then washed three times in $1 \times$ PBS for 10 min each wash. The sections were incubated in secondary antibody solution (1× PBS, $2 \%$ normal goat serum) for $60 \mathrm{~min}$ at room temperature; secondary antibodies (all from Fisher Scientific) include the following: goat anti-mouse Alexa Fluor 594 (AB_2534095, 1:500), goat anti-rabbit Alexa Fluor 594 (AB_2534091, 1:500), and DAPI (AB_2629482, 1:5000). Again, the sections were washed three times in $1 \times$ PBS for $10 \mathrm{~min}$ each wash. The sections were transferred to a frosted microscope slide (Fisher), coverslips were overlaid, and Immun-Mount (Thermo Scientific) mounting media were allowed to dry overnight. Images were collected from an Axioskop 2 plus microscope $(\times 10 / 0.25$ NA Achroplan, Carl Zeiss) using AxioVision (v4.8) software. Mean signal intensity for each section was recorded (ImageJ, v1.52i) by averaging across three segments of the region of interest, followed by subtraction of background signal intensity, and finally, the signal intensities of each section averaged together and converted into fold change relative to the respective control. The following ImageJ rectangle parameters (pixels) were used to measure the mean area intensity for each antibody: NeuN (CA1: $400 \times 150$ and DG: $100 \times 100$ ), synaptophysin (CA3: $100 \times 150$ ), GFAP (CA1: $250 \times 250$ ), Iba1 (CA1: $250 \times$ 250), and Tau-MC1 (CA1: $250 \times 250)$.

\section{Behavioral testing}

Mice were subjected to a battery of behavioral tasks. Unless otherwise noted, all mice were habituated to the lighting conditions ( $30 \mathrm{~lx}$ ) of the room for at least 30 min before behavioral testing. Each apparatus was cleaned with $70 \%$ ethanol between subjects to remove any scent cues that could alter behavior. For tasks that require multiple trials in the same day, mice were allowed to rest in between trials by serially assaying each animal in the cohort before assaying the same animal for the subsequent trial. Data were recorded using a digital webcam and were collected and analyzed using SMART software (Harvard Apparatus) or by hand. Recording and analysis setting for the software were identical between subjects for each respective task. For every task, mice that exhibited behavior $>2$ standard deviations away from the mean were excluded from the analysis.

\section{Open-field behavior}

To assess the locomotor activity and to test for any anxiety-like phenotypes, we utilized the open-field behavioral task. After habituation, individual mice were isolated in a new, clean cage for $10 \mathrm{~min}$ before beginning the assessment. For data acquisition, mice were placed into a $60 \times 42 \times 37 \mathrm{~cm}$ plastic box and allowed to freely move. Locomotor activity was recorded for $60 \mathrm{~min}$, measured based on the center of mass motion tracking, and analyzed for total distance traveled. 


\section{Y-maze}

Y-maze was performed based on a previous study [38]. Mice were habituated in the dark for $30 \mathrm{~min}$ and then habituated to the behavioral room lighting for $10 \mathrm{~min}$ before beginning the task. Mice were placed in arm " $\mathrm{A}$ " and allowed to freely explore for $10 \mathrm{~min}$. Mice were scored on alternation percentage. An alternation was defined as an animal exploring each of the three arms consecutively without reentering one of the previous two arms explored (i.e., entering " $A$ " followed by " $C$ " and then "B"). A trained observer scored this task. For an animal to be counted as entering an arm, all four paws had to enter the arm. Alternation percentage was calculated as the ratio of the number of alternations to the total number of turns. Animals that exhibited extreme stereotypy (i.e., only making left- or right-hand turns; defined as $>90 \%$ alternation) were excluded from the analysis.

\section{T-maze}

T-maze was performed based on a previous study [38]. On day 1, mice were habituated to the maze by allowing them to freely explore for $5 \mathrm{~min}$ with a milk reward in each arm. On day 2, mice are placed opposite to the top of the " $\mathrm{T}$ " arms and allowed to enter their innate preference side with no milk reward. This is repeated five times to confirm which side is the innate preference. On days 3-9, the arm for each animal's innate preference is closed and a milk reward is placed in the non-preference arm. Mice are trained four times per day against their innate preference. Mice are allowed up to $2 \mathrm{~min}$ to find the milk reward. If the animal does not find the milk reward, it is gently nudged to the milk reward. If an animal is nudged to or finds the milk reward, it is then blocked in with the milk reward for $30 \mathrm{~s}$ before being gently removed from the maze. On day 10 (probe trial day), mice are given one training run in the same manner as during training. Then, for the probe trial, the door to the innate preference arm is opened. Mice freely choose between the trained arm and the innate preference arm. Each animal is subjected to four trials, which are then converted to a percentage based on the number of correct choices (selecting a trained arm) for analysis.

\section{Novel object recognition task}

We performed the novel object recognition task in a similar manner as previously described [38]. Immediately before testing, individual mice were moved to a new, clean cage for $10 \mathrm{~min}$. Mice were then placed in an empty box with opaque walls (the same as used for open field). The mice were habituated inside the arena for 10 min per day for two consecutive days. On day 3 , the mice were introduced to two identical objects placed equidistant on the opposite ends of the arena. The mice freely moved around the arena and interacted with the objects for $10 \mathrm{~min}$. On day 4 , one of the familiar objects from the previous day was removed and replaced by a novel object. We had previously validated that the familiar and the novel object have equal salience when simultaneously introduced to naïve mice. Mice were considered to be interacting with either object when the snout of the animal was within a $2-\mathrm{cm}$ perimeter of the object. Video-recorded data for interaction time was standardized by converting to a discrimination index value where a score of 1 indicates interaction only with the novel object, 0 indicates equal interaction with either object (chance), and - 1 indicates interaction only with the familiar object. Discrimination index $=\left(\right.$ Time $_{\text {novel }}-$ Time $\left._{\text {familiar }}\right) /\left(\right.$ Time $_{\text {novel }}+$ Time $\left._{\text {familiar }}\right)$. Mice that did not interact for a total of at least $30 \mathrm{~s}$ (combined) with both objects were excluded.

\section{Barnes maze}

For the Barnes maze, we implemented a shortened protocol that was developed for AD mouse models [55]. The Barnes maze was composed of a circular, wooden platform with 20 circular holes, separated into 4 quadrants, drilled out around the edge of the platform equidistant from the center and one another. An escape box was placed underneath one hole. Eight unique features were placed around the maze for spatial differentiation. Lighting conditions were maintained at $30 \mathrm{~lx}$. Each day, mice were habituated to the testing room for $30 \mathrm{~min}$ before training or testing. Individual mice were transferred from their home cage to a clean cage for $5 \mathrm{~min}$ before training. Mice were given at least a 30-min inter-trial interval during training with all mice being trained serially before subsequent training trials for the same animal in the same day. On day 1 , mice were placed under a 2$\mathrm{L}$ glass beaker in the center of the maze for $15 \mathrm{~s}$. The beaker was then slowly moved to nudge the animal towards the hole with the escape box. Mice were given 2 min to fully enter the escape hole before being nudged into the escape hole. Mice were left in the escape box for $30 \mathrm{~s}$ before being returned to their home cage. On day 2 , mice were placed under a $1-\mathrm{L}$ opaque plastic beaker in the center of the maze for $15 \mathrm{~s}$. The beaker was removed, and mice were allowed to explore the maze for $2 \mathrm{~min}$. If mice had not found the escape box, they were trapped by the 2-L glass beaker and guided to the escape hole. If the animal did not enter the escape hole within $30 \mathrm{~s}$, the glass beaker was used to nudge the animal into the hole where the animal was kept for $30 \mathrm{~s}$ before being returned to its home cage. Training trials were repeated a total of three times. On day 3, training was performed as described for day 2 but for a total of 2 trials. No training was performed on day 4 . The probe trial was conducted on day 5 . The escape box was removed from the 
escape hole. Mice were placed under a 1-L opaque plastic beaker in the center of the maze for $15 \mathrm{~s}$. The plastic beaker was removed, digital video recording was started, and mice were allowed to explore the maze for $2 \mathrm{~min}$. After testing, mice were returned to their home cage. Recorded video data from the probe trial were analyzed to determine latency to find the target hole and percent of time spent in the target quadrant.

\section{Statistical analysis}

Graphs were created, and statistical analyses were performed using GraphPad Software (v5.0). All data is represented as mean \pm SEM. The sample size for each group is indicated in the figure legend. For all behavior analysis, data were analyzed by one-way ANOVA followed by Tukey post hoc test. Barnes maze quadrant time and the Y-maze timeline in Fig. 2 were analyzed differently; data were analyzed by two-way ANOVA followed by Bonferroni post hoc test. For all biochemical isolations and IHC statistical analysis, each dataset was analyzed by performing a one-sample $t$ test against a hypothetical value of 100 (normalized control-vehicle value) to determine if any samples were significantly different than controls. This was followed by a post hoc Student's $t$ test between the groups that were significantly different from control-vehicle. MC1 IHC was analyzed differently. Since control does not express MC1, only Student's $t$ test was applied to rTg4510 vehicle and compound-treated data.

\section{Results}

\section{Improved cognitive functions and synaptic integrity in rTg4510-crossed EAAT2 mice}

To assess the potential benefits of exclusively increased EAAT2 protein expression in rTg4510 mice, we crossed EAAT2 transgenic mice [48], which expressed 1.5-2-folds more EAAT2, with rTg4510 mice. At the age of 4 months, mice were subjected to the Y-maze test to assess the shortterm memory and novel object recognition test (NORT) to assess non-spatial long-term memory. The results showed that in the Y-maze test, rTg4510 mice selected arms at random while rTg4510 $\times$ EAAT2 mice preferentially selected unexplored arms similar to the control groups (Fig. 1a). In the NORT, rTg4510 mice again selected between a novel and familiar object at random while rTg4510 × EAAT2 mice preferentially interacted with the novel object like the control groups (Fig. 1b). This demonstrated that rTg4510 $\times$ EAAT2 mice exhibited improved cognitive functions compared with their rTg4510 littermates. It was reported that rTg4510 mice exhibit hyperactivity with agitative-like behavior, which correlates with the progression of tau pathology [47]. The hyperactive phenotype has been characterized by significantly increased locomotor activity in a novel environment. Hence, we conducted open-field tests by placing the mouse in a novel box and measured the distance traveled for $1 \mathrm{~h}$. The results showed that rTg4510 $\times$ EAAT2 mice still exhibited hyperactivity like their rTg4510 littermates (Fig. 1c).

Upon completion of behavioral assessment, mice were euthanized for pathological studies. To assess EAAT2 expression levels, we isolated gliosomes from the forebrain, which were enriched for perisynaptic astrocytic processes where EAAT2 is primarily localized. Western blot analysis of gliosome samples indicated that as expected, EAAT2 mice exhibited $\sim 1.5$-folds increase in EAAT2 protein levels, but, unexpectedly, EAAT2 protein levels were increased in rTg4510 mice $\sim 3.5$-folds relative to wild-type mice (Fig. 1d). Even more surprising, EAAT2 protein levels in $\mathrm{rTg} 4510 \times$ EAAT2 mice were significantly reduced relative to $\mathrm{rTg} 4510$ (Fig. 1d). Of note, when 2-month-old rTg4510 mice were treated with doxycycline (DOX) for 3 weeks to stop transgenic mutant tau expression, their EAAT2 protein levels were reduced in a similar manner (Additional file 1a, b), indicating that elevated EAAT2 expression was a consequence of mutant tau expression. We performed biotin labeling of cell surface proteins and found that the increased EAAT2 proteins found in $\mathrm{rTg} 4510$ mice were properly localized to the plasma membrane surface (Additional file 1c). In addition, we previously reported that EAAT2 is associated with the cholesterol-rich lipid raft microdomain of the plasma membrane and that the association with lipid raft is important for EAAT2 localization and function [56, 57]. We performed lipid raft preparations from the forebrains of $\mathrm{rTg} 4510$ mice and found that increased EAAT2 was properly localized in lipid raft microdomains as well (Additional file 1d). These results indicated that increased EAAT2 is functional and not an accumulation of inactive aggregates. For undetermined reasons, increased germline expression of EAAT2 partially normalized EAAT2 protein levels in rTg4510 $\times$ EAAT2 mice.

To assess the synaptic integrity, we isolated synaptosomes from the forebrain, which were enriched for neuronal processes. Postsynaptic density 95 (PSD-95) levels, a postsynaptic density protein, were measured by Western blot analysis. The results showed that rTg4510 mice exhibited significantly reduced PSD-95 levels in synaptosomes, suggesting a reduced number of synapses, which was normalized in $\mathrm{rTg} 4510 \times$ EAAT2 mice (Fig. 1e) Furthermore, we conducted immunohistochemical staining using NeuN antibodies to examine hippocampal neurodegeneration. The results showed a significant reduction of NeuN immunostaining in the CA1 ( 71\% reduction) and dentate gyrus (DG, $\sim 57 \%$ reduction) regions of $\mathrm{rTg} 4510$ mice compared to their wild-type littermates (Fig. 1f, g). rTg4510 × EAAT2 littermates exhibited less neuronal loss in the CA1 ( 54\% reduction) 

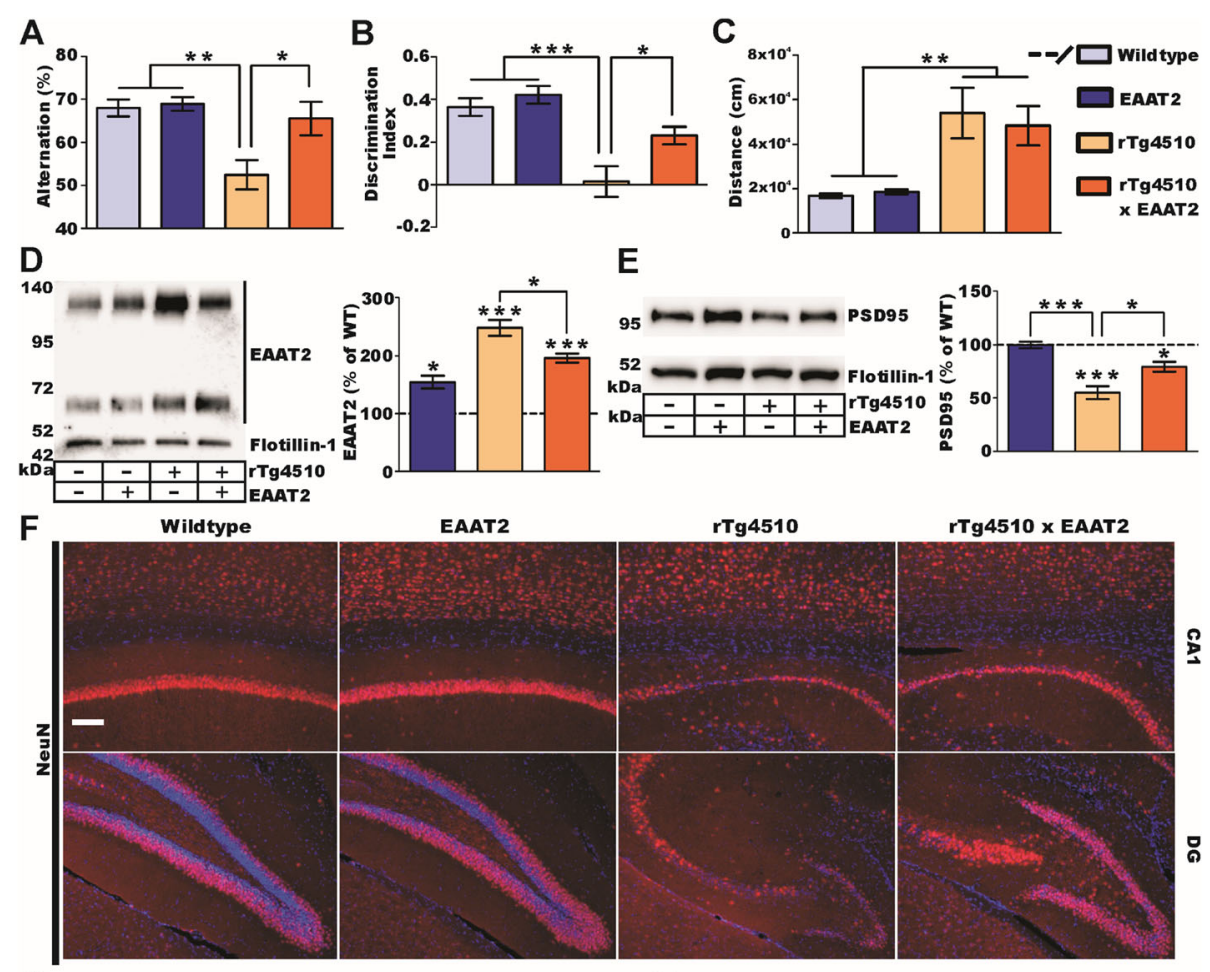

rTg4510 X EAAT2

G

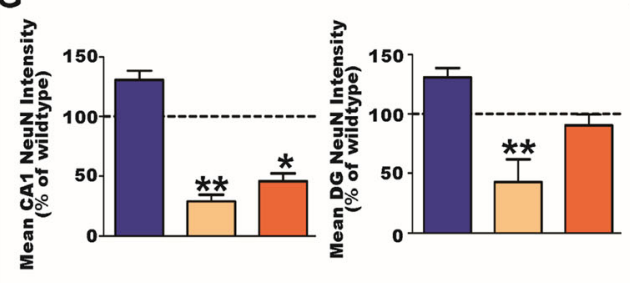

$\mathbf{H}_{72}$

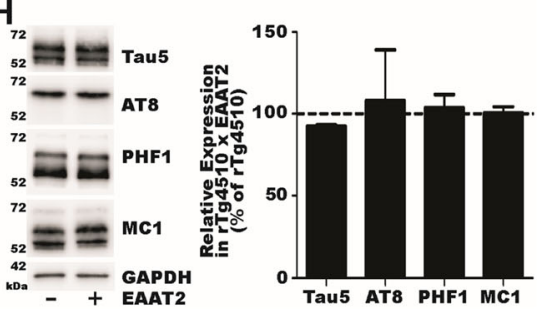

Fig. 1 Transgenic overexpression of EAAT2 protects against mutant tau-mediated pathology. a-c Results of behavioral analysis $(n=13 / 13 / 10 / 10$, respectively). rTg4510 mice show working memory deficits in the Y-maze (a) and recognition memory deficits in the NORT (b), but EAAT2 overexpression protected against these cognitive deficits. $\mathbf{c}$ However, EAAT2 overexpression did not protect against open-field hyperactivity behavior in rTg4510 mice. $\mathbf{d}$, e Biochemical assessment of tripartite synapse pathology ( $n=4 /$ group). $\mathbf{d}$ As expected, EAAT2 transgenic mice expressed more EAAT2 in gliosomes than wild-type mice, but, unexpectedly, rTg4510 mice express even more EAAT2. rTg4510 × EAAT2 mice paradoxically exhibit reduced EAAT2 in gliosomes, partially normalizing EAAT2 towards control levels. e Synaptic integrity was reduced in rTg4510 mice (as assessed by PSD-95) in synaptosomes, while EAAT2 overexpression protected against synaptodegeneration. $\mathbf{f}$ NeuN immunohistochemistry showed that EAAT2 overexpression provided modest protection against neurodegeneration in rTg4510 mice. g Quantification of NeuN immunostaining. h Overexpression of EAAT2 in rTg4510 mice did not alter total tau, phosphorylated tau, or Sarkosylinsoluble tau aggregates. ${ }^{*} P<0.05,{ }^{*} P<0.01, P<0.001$

or dentate gyrus ( $\sim 10 \%$ reduction), suggesting improved neuronal survival (Fig. 1f, g). Of note, the efficacy observed was not due to tau transgene suppression since rTg4510 $\times$ EAAT2 mice expressed equal levels of transgenic mutant tau as their rTg4510 littermates as assessed by Western blot (Fig. 1h). In addition, we examined phosphorylated tau levels by Western blot analysis of hippocampal lysates using PHF1, AT8, and MC1 antibodies. The results showed that phosphorylated tau levels were not changed in $\mathrm{rTg} 4510 \times$ EAAT2 mice compared to their rTg4510 littermates (Fig. 1h). Taken together, these results indicate that transgenically increased EAAT2 expression in $\mathrm{rTg} 4510$ mice moderately protects cognitive function and synaptic integrity, while only modestly protecting against neurodegeneration, but has no effect on tau hyperphosporylation.

\section{LDN/OSU-0215111 principally blocked disease} progression at the moderate disease stage Next, we investigated if LDN/OSU-0215111 could provide beneficial effects in rTg4510 mice. Prior to performing the efficacy study, two preliminary experiments were conducted. First, we determined the optimal oral dose of LDN/OSU-0215111 in wild-type mice using EAAT2 as the marker. Mice were treated with the compound at 1 , $2.5,5,10,20$, and $40 \mathrm{mg} / \mathrm{kg}$ PO daily for 7 days. Western 
blot analysis of gliosomes prepared from the forebrain of treated mice showed a dose-dependent increase of EAAT2 with maximal induction observed at doses of 10 , 20, and $40 \mathrm{mg} / \mathrm{kg}$ (Fig. 2a). We then tested the dose of $10 \mathrm{mg} / \mathrm{kg}$ in 4-month-old rTg4510 mice. The results showed that a single dose of the compound resulted in a significant downregulation of EAAT2 (Fig. 2b), as was observed in rTg4510 $\times$ EAAT2 mice (Fig. 1d). We also assessed the effects on the synapse by examining the synaptic proteins in synaptosomes prepared from the forebrain of treated mice. The results showed that synaptic proteins, including PSD-95, NR2B (NMDA receptor subunit), and synaptophysin (pre-synaptic protein), were significantly decreased in $\mathrm{rTg} 4510$ mice but were partially restored following a single dose of compound (Fig. 2c). Similar results were also observed when we examined PSD-95 levels in postsynaptic density complexes prepared from the hippocampal regions. These results indicated that a single dose of LDN/OSU0215111 at $10 \mathrm{mg} / \mathrm{kg}$ was capable of partially normalizing EAAT2 levels and restoring synaptic integrity in rTg4510 mice. We therefore chose the dose of $10 \mathrm{mg} / \mathrm{kg}$ for the studies below. Second, we determined the appropriate age to begin the treatment. We sought to identify a time point that represents the early symptomatic stage. Y-maze tests were conducted at 1,2, and 3 months of age. We found that rTg4510 mice already exhibited impaired functioning in the test at 1 month, further deterioration at 2 months, and a leveling off between 2 and 3 months of age (Fig. 2d). We therefore determined treatment would begin at 2 months of age.

The efficacy study was conducted as follows. Littermatematched mice with equal distribution of sexes were divided into four groups: control (wild-type)/vehicle, control/compound, rTg4510/vehicle, and rTg4510/compound ( $n=30-35$ per group). Mice received compound at 10 $\mathrm{mg} / \mathrm{kg} /$ day by voluntary ingestion (PO) of compound in honey emulsion starting at 2 months of age. At 4 months old (moderate disease stage), mice were subjected to open-field tests to assess agitation-like behavior and then three cognitive tests, including Y-maze, NORT, and Tmaze tests. Examiners were blinded regarding the treatment. Upon completion of behavioral assessment, a subset of mice ( $n=10-12$ per group) was euthanized for pathological studies and the rest of mice continued receiving treatment. At 8 months old (severe disease stage), mice again were subjected to open-field tests and cognitive tests. Following behavioral testing, mice were euthanized for pathological studies or electrophysiological studies.

The results of behavioral and pathological assessments at 4 months of age are presented in Fig. 3. No obvious differences were observed between males and females (male/ female $n$ value: control-vehicle, 15/12; control-compound, 14/13; rTg4510-vehicle, 10/13; rTg4510, 12/15). Open- field results indicated that compound treatment completely ameliorated agitative-like behavior in rTg4510 mice (Fig. 3a). In all three cognitive tests, vehicle-treated rTg4510 mice showed very significant impairments. Importantly, compound treatment significantly improved short-term memory (Y-maze; Fig. 3b), non-spatial longterm memory (NORT; Fig. 3c), and spatial learning memory (T-maze; Fig. 3d). It is notable that compound-treated rTg4510 mice were statistically indistinguishable from control mice in NORT and T-maze tasks, indicating that compound treatment almost completely prevented cognitive decline in rTg4510 mice. Consistently, follow-up pathological studies showed that PSD-95 levels in the postsynaptic density complexes prepared from the hippocampus were markedly decreased in vehicle-treated rTg4510 mice but were significantly restored to nearly normal levels in compound-treated rTg4510 mice (Fig. 3e). It is notable that synaptic PSD-95 protein loss was not found in the prefrontal cortex, suggesting that overt disease pathology is limited to the hippocampus at this stage. We examined EAAT2 levels in the hippocampus by performing crude plasma membrane preparations to assess membrane-bound EAAT2. The results showed an increase in the expression of EAAT2 in vehicle-treated rTg4510 mice as was previously observed in Figs. 1d and $2 \mathrm{~b}$, which were partially normalized by the compound treatment (Fig. 3f).

Furthermore, immunohistochemical analysis of hippocampal regions revealed that vehicle-treated $\mathrm{rTg} 4510$ mice exhibited severe neurodegeneration in the CA1 and the DG region, as assessed by NeuN immunostaining, but the neuronal loss was almost completely prevented in compound-treated rTg4510 mice (Fig. 3g). Moreover, expression of the pre-synaptic marker synaptophysin (a proxy for synaptic integrity) was completely lost in the CA3 region in vehicle-treated rTg4510 mice but was well-preserved in compound-treated rTg4510 mice (Fig. 3g). Neurofibrillary tangles, which were detected in the CA1 region of vehicle-treated $\mathrm{rTg} 4510$ mice by $\mathrm{MC} 1$ immunostaining, were significantly reduced in compound-treated rTg4510 mice (Fig. 3g). We examined astroglial activation and gliosis by GFAP (glial fibrillary acidic protein) immunostaining and found a remarkable increase in GFAP immunoreactivity in the CA1 region of vehicle-treated rTg4510 mice, which was significantly decreased in compound-treated rTg4510 mice (Fig. 3g). We also examined microglial activation by Iba1 (ionized calcium-binding adaptor molecule 1) immunostaining, but no increase in Iba1 immunoreactivity was found in $\mathrm{rTg} 4510$ mice at this age. Taken together, we found that when treatment began at 2 months of age, rTg4510 mice demonstrated near-normal cognition and behavior, almost indistinguishable from control mice, at 4 months old. This indicates the exceptional efficacy of LDN/OSU-0215111. 
A
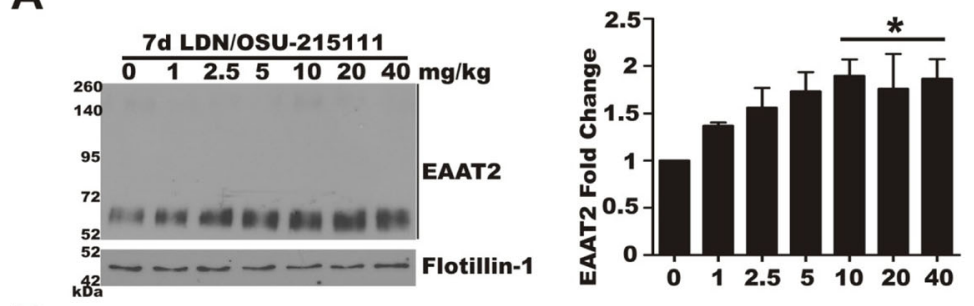

B
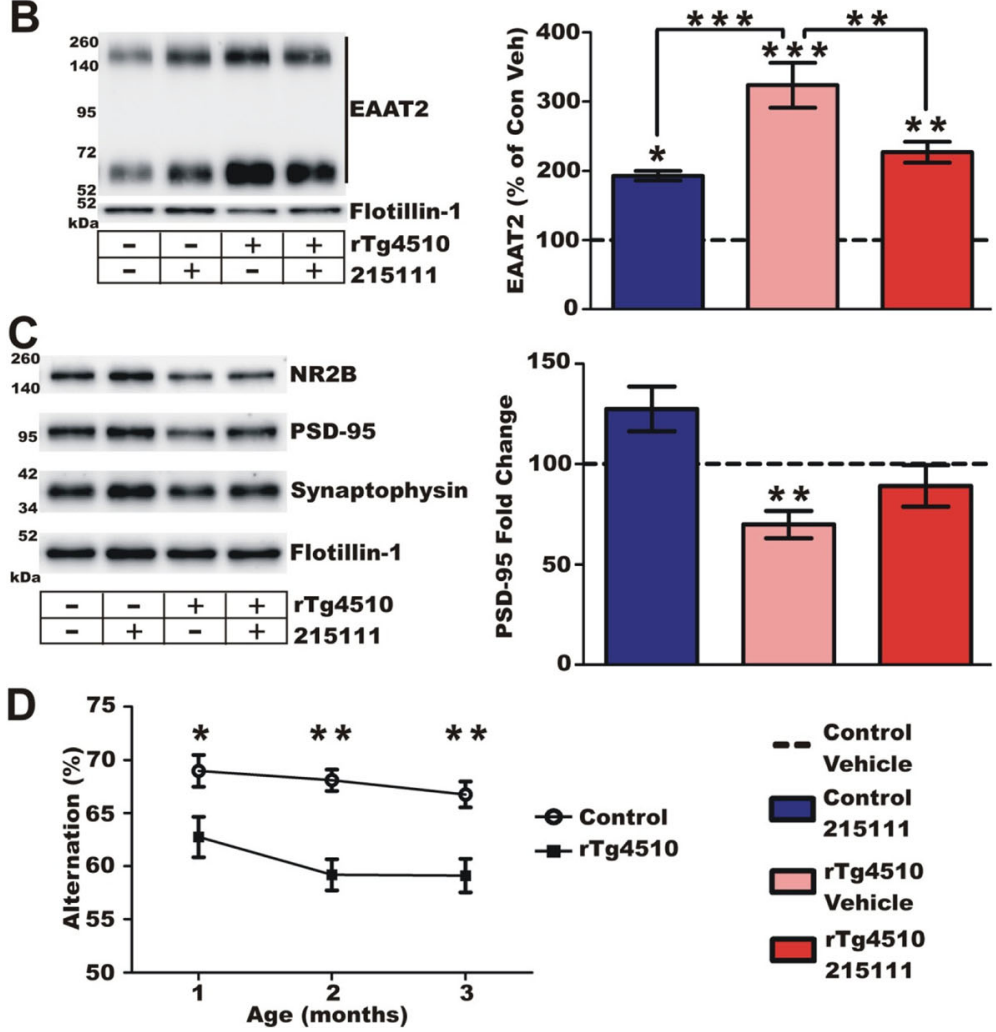

Fig. 2 LDN/OSU-0215111 dose and treatment start time selection. a Control mice were treated with LDN/OSU-0215111 at doses indicated for 7 days $(n=$ 3/group). Doses of 10, 20, and $40 \mathrm{mg} / \mathrm{kg}$ were found to significantly upregulate gliosome EAAT2. We therefore selected a treatment dose of $10 \mathrm{mg} / \mathrm{kg}$ for use in rTg4510 mice. b Similar to transgenic EAAT2 overexpression, a single compound treatment upregulated EAAT2 in gliosomes in control mice ( $n=4 /$ group). Likewise, compound treatment in rTg4510 mice reduced EAAT2 expression c rTg4510 mice exhibited a significant decrease in synaptosomal PSD95 expression; however, a single treatment of compound normalized PSD-95 expression comparable to controls ( $n=4 / g r o u p)$. $\mathbf{d}$ Behavioral deficits in the Y-maze were seen at 1 month of age in rTg4510 mice which further deteriorated at 2 months of age and plateaued at 3 months $(n=25$ and 29 , respectively). We therefore chose 2 months of age for treatment start. ${ }^{*} P<0.05,{ }^{* *} P<0.01$, ${ }^{* *} P<0.001$

\section{LDN/OSU-0215111 continues to provide protection at the} severe disease stage

Figure 4 shows the results of behavioral and pathological assessments at 8 months old. No obvious differences were observed between males and females (male/female $n$ value; control-vehicle, 19/15; control-compound, 12/9; rTg4510-vehicle, 11/17; rTg4510, 16/16). The agitativelike behavior was still normalized by compound treatment, as assessed by open-field tests (Fig. 4a). For the cognitive assessment, LDN/OSU-0215111 still significantly prevented short-term memory decline (Y-maze; Fig. 4b) and non-spatial long-term memory decline (NORT; Fig. 4c). We utilized the Barnes maze test in lieu of the T-maze test to assess spatial learning memory. Vehicle-treated rTg4510 mice took significantly longer to find the target hole (Fig. 4d) and spent significantly less time in the target quadrant of the maze (Fig. 4e). On the other hand, compound-treated rTg4510 mice found the target hole significantly faster (Fig. 4d) and spent more time in the target quadrant (Fig. 4e). These behavior studies indicated that compound treatment still provided significant beneficial effects to cognitive functions at this late stage of the disease.

Follow-up pathological studies showed that vehicletreated rTg4510 mice exhibited very significantly reduced PSD-95 levels in the postsynaptic density 


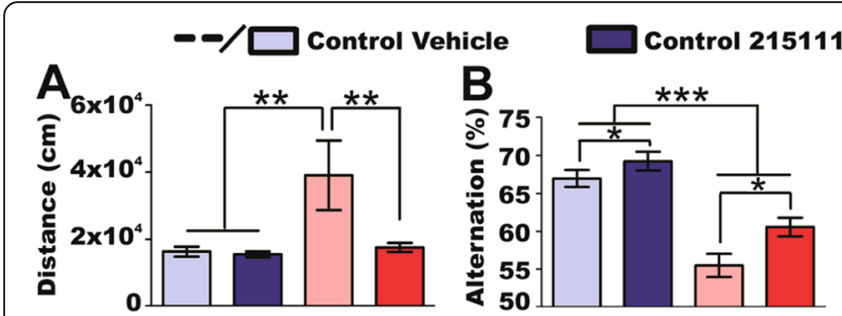

$\mathbf{E}$
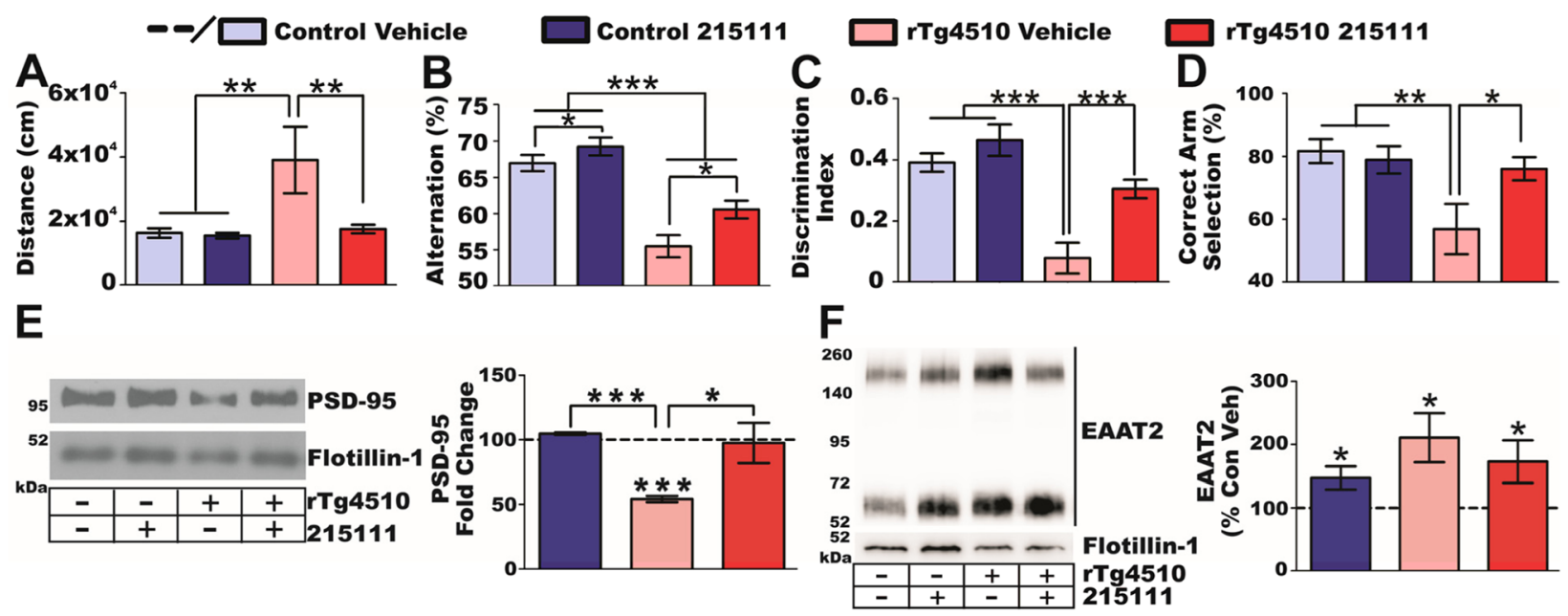

\section{G}
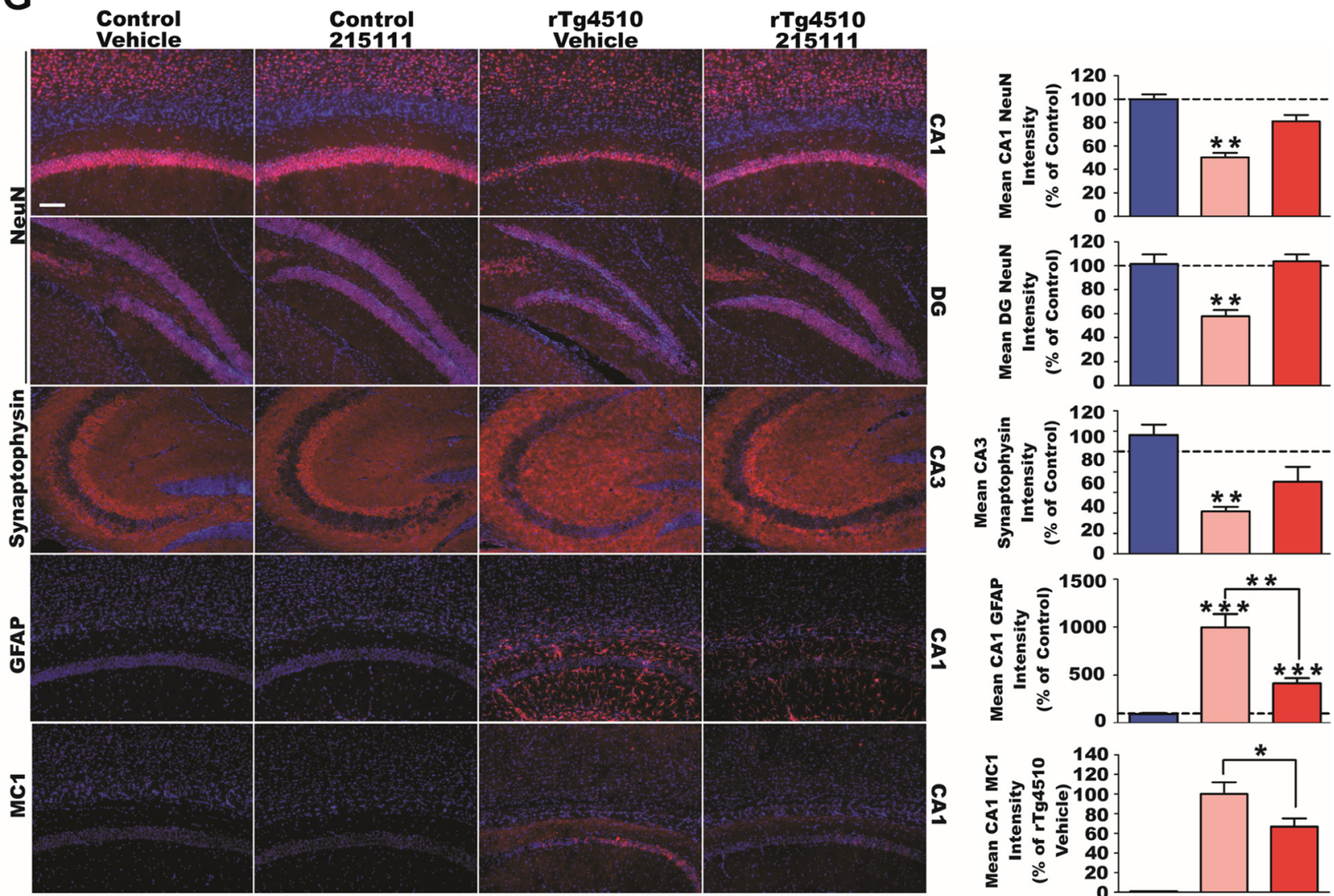

Fig. 3 LDN/OSU-0215111 efficacy at moderate disease stage. a-d Results of behavioral battery ( $n=27 / 27 / 23 / 27$, respectively). Compound treatment normalized hyperactivity in the open field (a), short-term memory in the Y-maze (b), recognition memory in the NORT, (c) and cognition in the T-maze (d). e PSD-95 expression in hippocampal postsynaptic densities of rTg4510 was significantly reduced ( $n=5 / 5 / 4 / 4$, respectively), showing synaptic loss. Compound treatment in rTg4510 mice restored synaptic integrity indistinguishable from controls. $\mathbf{f}$ Hippocampal crude membrane preparations $(n=5 / 5 / 4 / 4$, respectively) revealed increased EAAT2 in the rTg4510 vehicle group which was partially normalized by compound treatment. $\mathbf{g}$ Representative immunohistochemistry images of hippocampal subregions ( $n=4$ animals/group; average of $\geq 3$ sections/animal). The cell nuclei were stained by DAPI (blue). Quantification (right) is percent change relative to control vehicle (dashed line), except MC1 (compared to rTg4510 vehicle). Control groups exhibited no differences. NeuN immunostaining demonstrated significant neurodegeneration in CA1 and DG of rTg4510 mice, which was prevented by compound treatment. Compound treatment maintained CA3 synaptic integrity (synaptophysin) and significantly reduced neurofibrillany tangle accumulation (MC1) in CA1 of rTg4510 mice. Finally, GFAP immunoreactivity was significantly increased in both rTg4510 groups, but compound treatment reduced gliosis. Scale bar $=100 \mu \mathrm{m} .{ }^{*} P<0.05,{ }^{* *} P<0.01,{ }^{* * *} P<0.001$ 

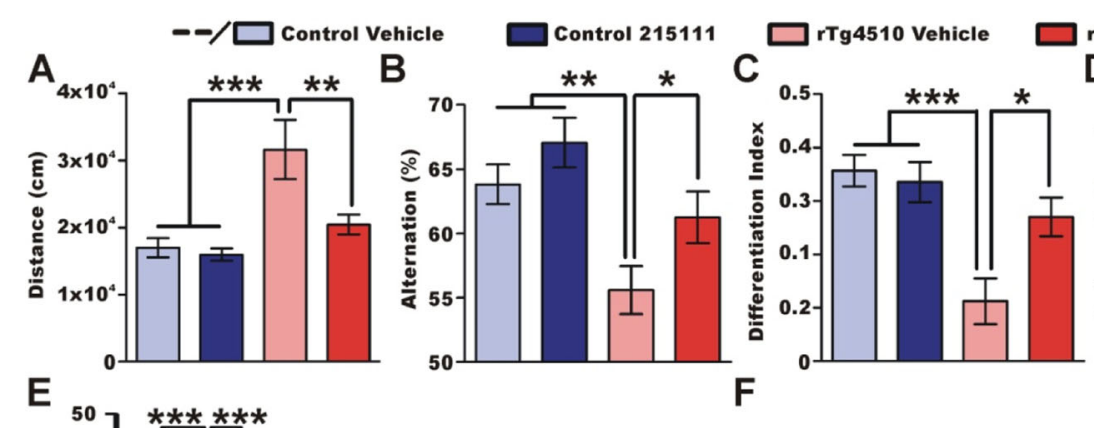

rTg4510 215111

D
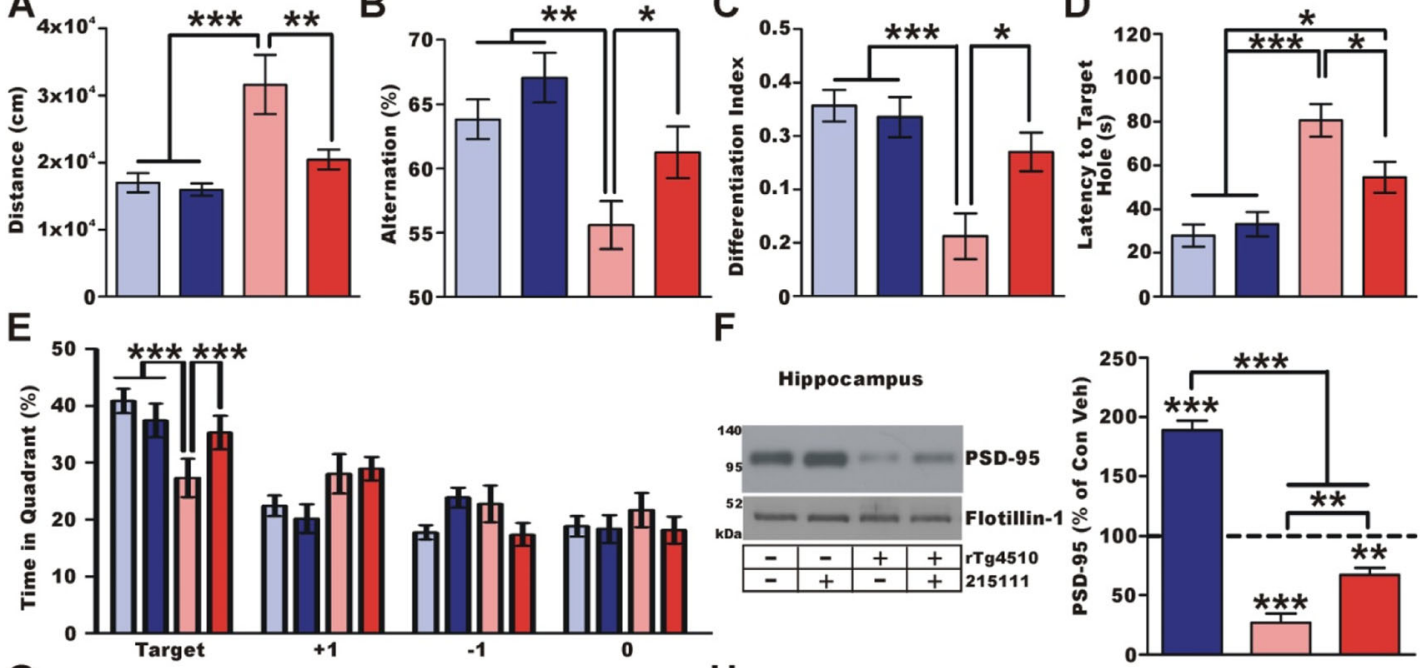

Hippocampus

G Prefrontal Cortex

H

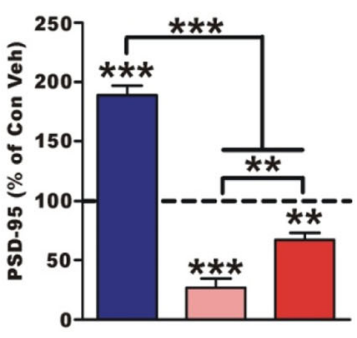

.
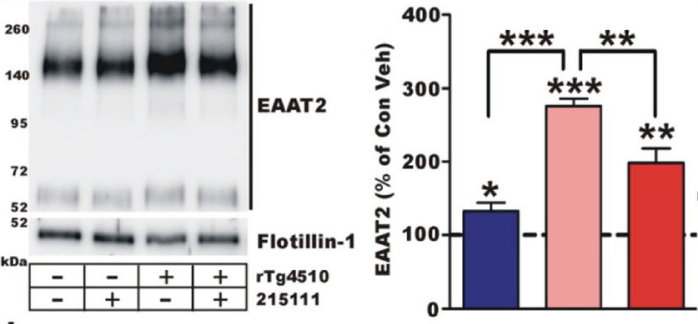

Prefrontal Cortex

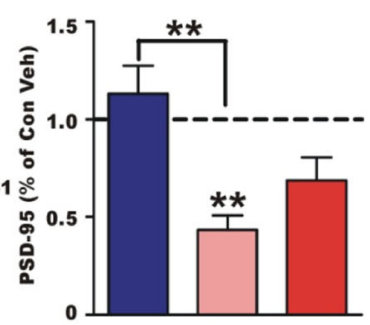

I
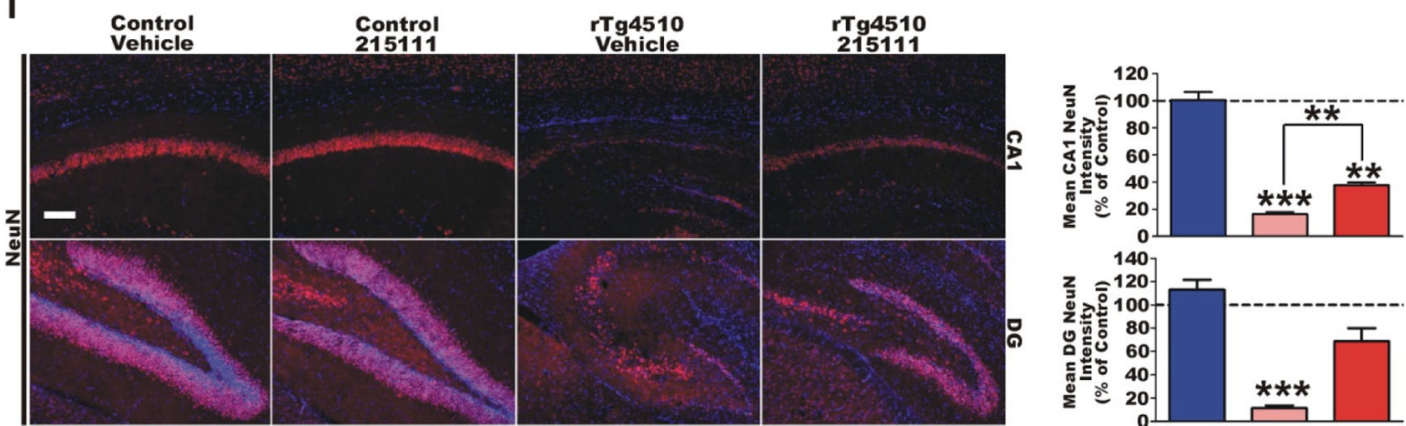

140

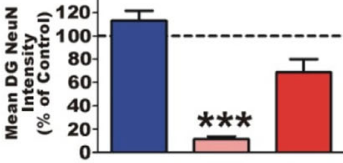

등
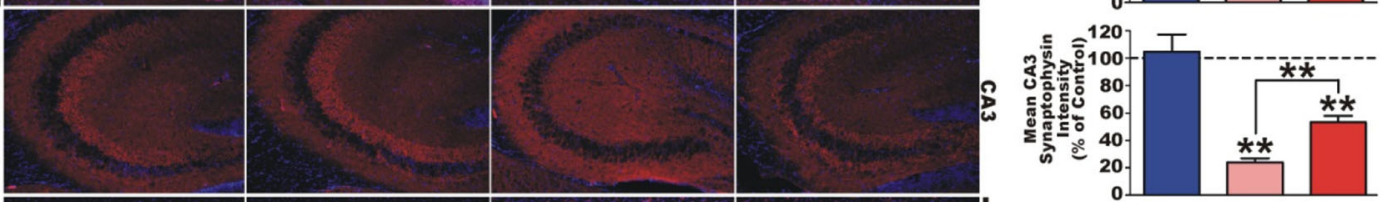

⿺ㅏㄴ
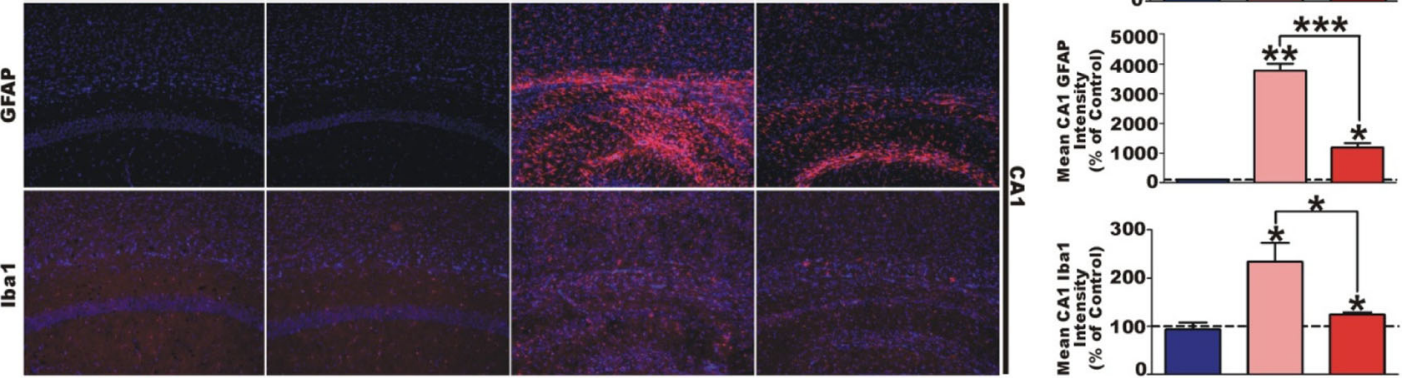

Fig. 4 (See legend on next page.) 
(See figure on previous page.)

Fig. 4 LDN/OSU-0215111 efficacy at severe disease stage. a-e Results of behavioral battery ( $n=34 / 21 / 28 / 32$, respectively). Long-term compound treatment continued to prevent the development of agitation-like behavior (a) while maintaining improved cognition in Y-maze (b) recognition memory in the NORT (c) and spatial memory in Barnes maze (d, e) in rTg4510 mice. $\mathbf{f}$ Loss of PSD-95 in rTg4510 hippocampal postsynaptic densities was robust ( $n=8 /$ group); however, compound treatment continued to significantly reduce synaptodegeneration. $\mathbf{g}, \mathbf{h}$ PFC tripartitesynapse integrity ( $n=4 /$ group). Similar to the hippocampus at 4 months, rTg4510 PFC postsynaptic densities exhibit decreased PSD-95 expression (g) and increased crude membrane EAAT2 expression (h). Compound treatment partially normalized both phenotypes. i Representative

immunohistochemistry images of the hippocampus ( $n=4 /$ group). Cell nuclei were stained by DAPI (blue). Quantification (right) is percent change relative to control vehicles (dashed line). Neurodegeneration (as assessed by NeuN) was observed in CA1 and DG of rTg4510 vehicle mice;

however, compound treatment significantly reduced neuronal loss. A similar pattern was observed for synaptic integrity (synaptophysin). rTg4510 mice exhibit increased GFAP and Iba1 in CA1, which was reduced and partially normalized by compound treatment. Scale bar $=100 \mu \mathrm{m}$. ${ }^{*} P<$ $0.05,{ }^{* *} P<0.01,{ }^{* * *} P<0.001$

complexes prepared from the hippocampi (Fig. 4f). Compound-treated rTg4510 mice maintained significantly higher PSD-95 expression than vehicle-treated rTg4510 mice. Unlike at 4 months of age, EAAT2 expression in the hippocampus showed no difference between treated and untreated rTg4510 mice. However, by 8 months, the prefrontal cortex exhibited synaptic pathology, similar to what was observed in the hippocampus at 4 months old. We found a significant increase of EAAT2 expression and a significant loss of PSD-95 protein in the prefrontal cortex of vehicle-treated rTg4510 mice (Fig. 4g, h). Compound treatment partially normalized the expression of both PSD-95 and EAAT2.

Immunohistochemical analysis of the hippocampal regions revealed that at this stage of disease progression, both vehicle- and compound-treated rTg4510 mice exhibit significant neurodegeneration in the CA1 and DG regions, as assessed by NeuN immunostaining. However, LDN/OSU-0215111-treated rTg4510 mice showed significantly reduced levels of neurodegeneration in both regions (Fig. 4i). In addition, the expression of synaptophysin was partially preserved in compound-treated rTg4510 mice (Fig. 4i). Both rTg4510 groups exhibit increased GFAP immunoreactivity; however, compound treatment significantly reduced GFAP immunoreactivity in the CA1 (Fig. 4i). Vehicle-treated rTg4510 mice had a significant increase in Iba1 immunoreactivity. The increase in Iba1 immunoreactivity was significantly lower in compound-treated mice (Fig. 4i). Overall, LDN/OSU0215111 continues to provide disease-modifying and disease-delaying benefits against all phenotypes tested after long-term treatment.

\section{LDN/OSU-0215111 benefits are sustained 1 month after treatment cessation}

To determine how long the benefits of treatment could persist, a cohort of compound-treated rTg4510 mice was switched to vehicle treatment (STOP treatment) at 8 months of age. One-month post-treatment cessation, behavior tests, followed by pathological studies, were conducted to compare the STOP treatment rTg4510 group with the continued treatment
rTg4510 group, the vehicle rTg4510 group, and the control vehicle group. Surprisingly, locomotor activity levels in the open field remained normalized in the STOP treatment group (Fig. 5a). NORT results indicated that long-term memory was preserved in the STOP treatment rTg4510 mice (Fig. 5b). For both behavioral tasks, the STOP treatment and the continued treatment groups performed essentially identically. Follow-up pathological studies showed that all rTg4510 groups exhibited significant reductions in PSD-95 levels in the postsynaptic densities of the hippocampus; however, the STOP treatment group showed a significant increase, approximately twofolds, in PSD-95 levels relative to the vehicle group (Fig. 5c). The expression level of PSD-95 in the STOP treatment group was indistinguishable from the continued treatment group. These results indicated that LDN/ OSU-0215111 directly modifies the disease pathology and does not act as a palliative care agent.

We further conducted electrophysiological studies to examine the integrity of the hippocampal synaptic circuit. We analyzed the changes to LTP in the hippocampal CA3-CA1 circuit along the Schaffer collateral pathway. By only looking at the I/O curves, it was clear that all three rTg4510 groups had reduced synaptic strength (Fig. 5d). However, the vehicle rTg4510 group had the most substantially reduced synaptic strength while the continued treatment and the STOP treatment groups showed an intermediate reduction. The vehicle rTg4510 group exhibited very little LTP (Fig. 5e). Both the STOP treatment and continued treatment rTg4510 groups were found to have significantly enhanced LTP relative to the vehicle $\mathrm{rTg} 4510$ group that was statistically indistinguishable from the control vehicle group. This is surprising because, although both continued treatment and STOP treatment groups exhibited neurodegeneration and reduced synaptic integrity relative to controls, both were able to form relatively normal LTP. Of note, compound-treated controls were found to have highly elevated levels of LTP after stimulation compared to vehicle-treated controls suggesting these mice exhibit enhanced synaptic plasticity. 


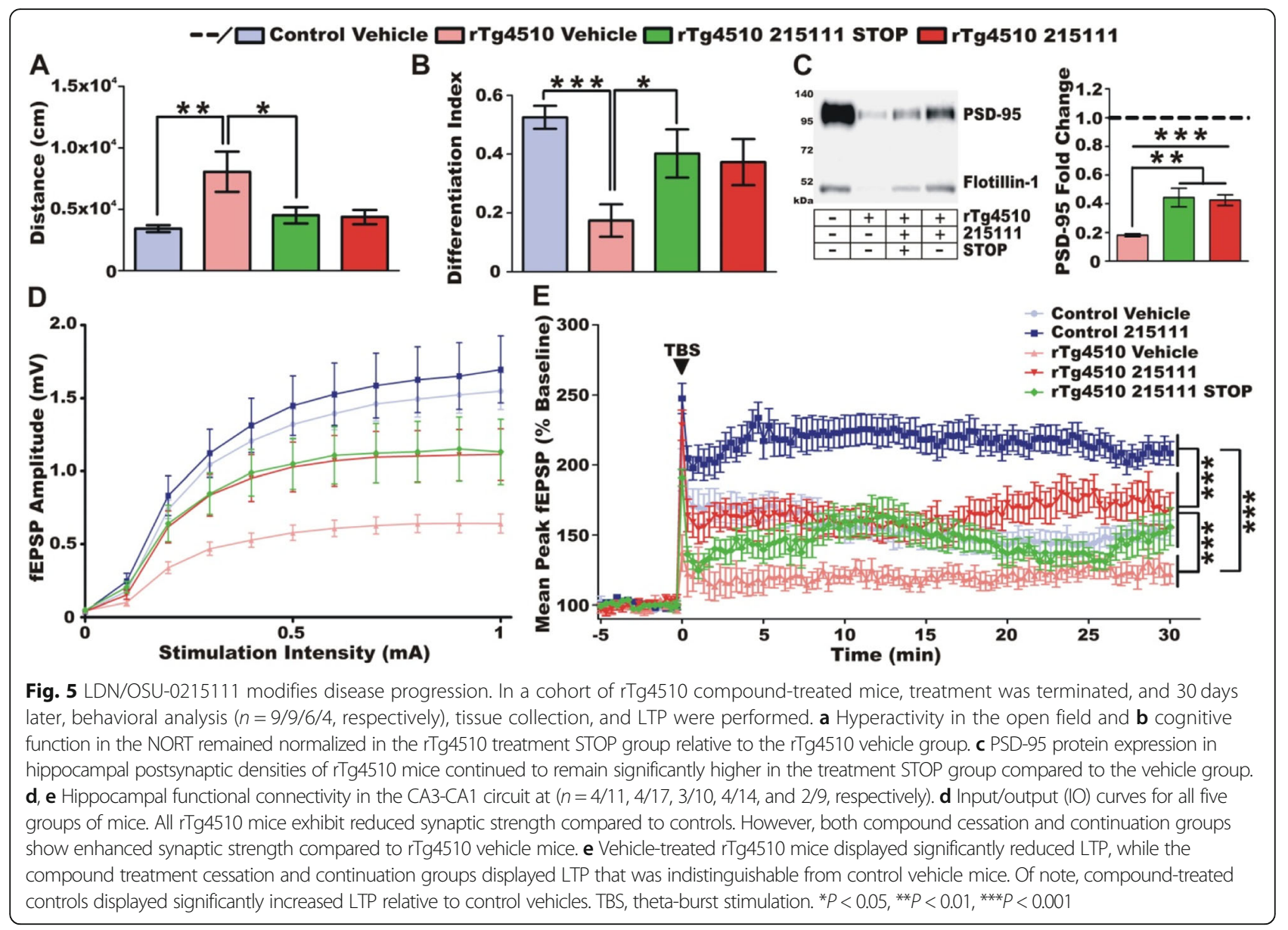

\section{LDN/OSU-0215111 reduces tau hyperphosphorylation/ deposition putatively by modifying kinase activity}

As shown in Fig. 3g, we observed reduced neurofibrillary tangles in long-term compound-treated rTg4510 mice. We, therefore, investigated if the compound could reduce toxic forms of tau. We examined tau expression levels in total cell lysates (TCL) and Sarkosyl-insoluble fractions (P3) prepared from the forebrains of rTg4510 mice that were harvested at 4 months old (after 2 months of treatment) by Western blot analysis. Four antibodies, which recognized different phosphorylation sites or pathological forms of tau, were used: PHF1 recognized Ser 396 and Ser404; AT8 recognized Ser202 and Thr205; MC-1 recognized neurofibrillary tangles, and Tau 5 recognized all of tau (phosphorylated and nonphosphorylated isoforms). The results showed a robust decrease in the expression of all forms of phosphorylated tau tested in compound-treated rTg4510 samples, both TCL and P3 fractions (Fig. 6a). There was an especially significant reduction in the 64-kDa (hyperphosphorylated) variant for each antibody tested; it has been reported that the $64-\mathrm{kDa}$ variant was strongly correlated with neurodegeneration [53]. Importantly, transgene expression of tau was not negatively affected as there was no reduction in total tau; rather, a slight increase in the level of total tau expression was observed, which we attributed to an increased number of surviving neurons.

Next, we asked if this reduction in tau phosphorylation and deposition was a direct effect of the compound or was due to compensatory changes secondary to longterm compound treatment. To accomplish this, naïve rTg4510 mice were given a single dose of vehicle or LDN/OSU-0215111, and $24 \mathrm{~h}$ later, the forebrains were collected and processed for Sarkosyl isolation. We found that, even after a single dose, there was a significant decrease in pTau (AT8 and PHF1), but no change in total tau (Tau-5) or tau tangles (MC1) in TCL (Fig. 6b, open bars). Even more prominently, there was a very clear reduction of all forms of tau in the P3 fraction (Fig. 6b, black bars). This indicated a direct effect of compound mediating reduced pTau and suggested that compound may activate/inhibit a kinase/phosphatase to mediate this effect. To identify which kinase/phosphatase may be involved, forebrain TCL samples were collected from rTg4510 mice $1 \mathrm{~h}$ after a single dose. The phosphorylation (activation) state of most kinases that have been 

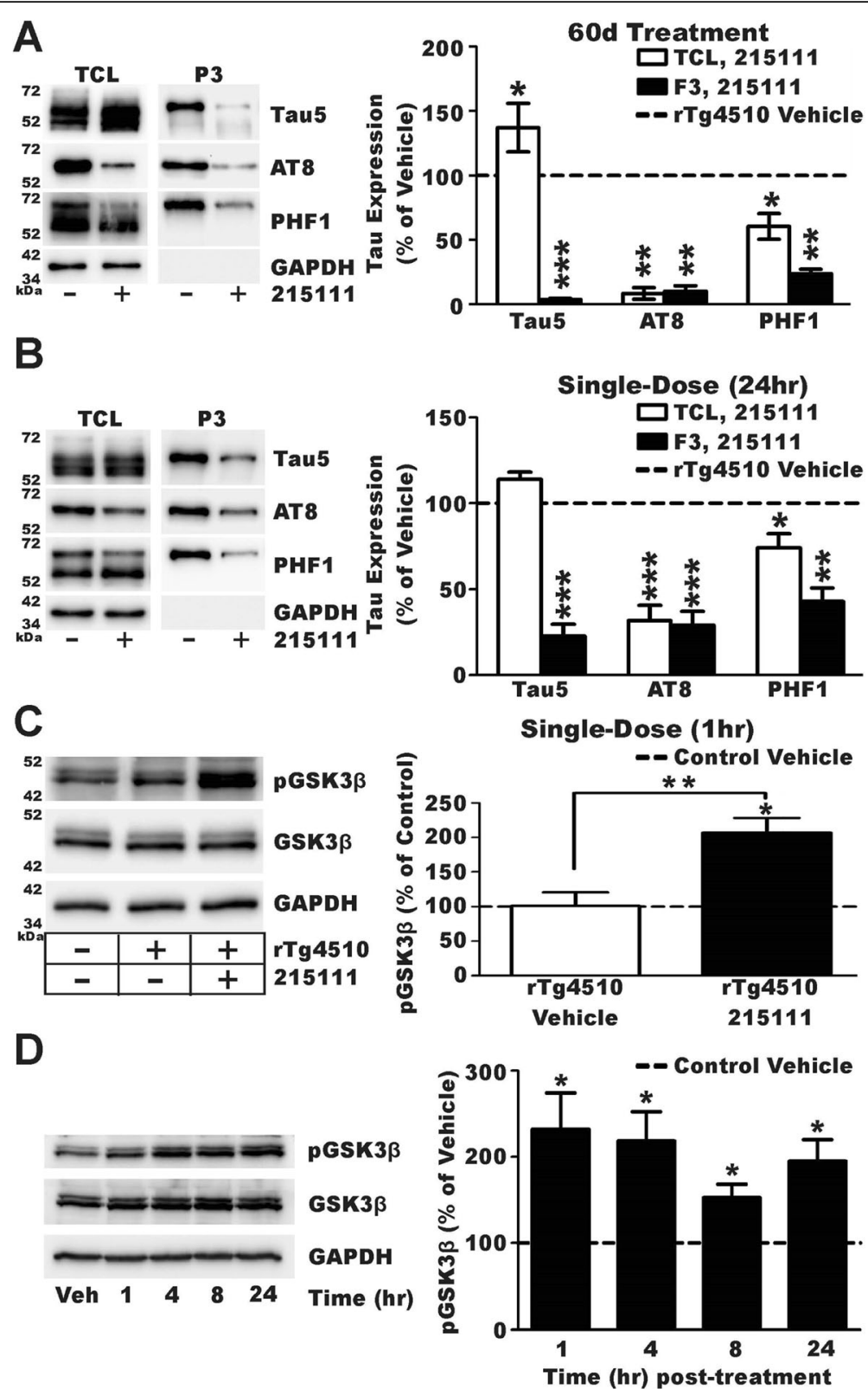

Fig. 6 LDN/OSU-0215111 reduces pTau and inhibits GSK3ß. a, b Effect of compound treatment on phosphorylated tau in total lysates (TCL, open bars) and in the Sarkosyl-insoluble (P3, black bars) fraction ( $n=4$ /group). Dashed line represents the expression in the rTg4510 vehicle group. $\mathbf{a}$ Long-term compound treatment slightly, but significantly, increased total tau (Tau5) expression in the forebrain and yet reduced phosphorylated (AT8 and PHF1). There was a very significant reduction of total tau in the P3 fraction and subsequent reductions of phosphorylated tau expression. $\mathbf{b}$ Single dosing of compound did not change the total forebrain tau expression (Tau5); however, a significant reduction of phosphorylation in PHF1 and a more robust reduction of AT8 phosphorylation were observed. In the P3 fraction, total tau was reduced and, subsequently, so was all aberrant forms of tau. c Basal inhibitory phosphorylation of GSK3 $\beta$ at Ser9 in rTg4510 vehicle mice was similar to control levels ( $n=4 / \mathrm{group}$ ). Compound treatment significantly increased phosphorylation of GSK3 $\beta$ at Ser9 in rTg4510 mice approximately twofolds within $1 \mathrm{~h}$ of treatment, and $\mathbf{d}$ this increased GSK3 $\beta$ phosphorylation is maintained up to $24 \mathrm{~h}$ after a single dose. ${ }^{*} P<0.05,{ }^{*} P<0.01,{ }^{* *} P<0.001$

reported to target tau as a substrate was assessed. Of all the kinases tested, only GSK3 $\beta$ showed a significant change in phosphorylation state-twofold upregulation of phosphorylation at Ser9 (Fig. 6c). Furthermore, this enhanced inhibitory phosphorylation of GSK3 $\beta$ was maintained for up to $24 \mathrm{~h}$ after a single dose (Fig. 6d). This form of phosphorylation inhibits GSK3 $\beta$ activity $[58,59]$. Therefore, inactivation of the GSK3 $\beta$ kinase may mediate reduced tau phosphorylation in $\mathrm{rTg} 4510$ mice after compound treatment. 


\section{Discussion}

In the present study, we found that LDN/OSU-0215111 exhibited a profound, disease-modifying efficacy in rTg4510 mice. At the moderate disease stage, LDN/OSU0215111-treated mice behaved essentially indistinguishable from control mice and showed profound protection against progressive tau-mediated pathology. Even at the severe disease stage, LDN/OSU-0215111 continued to provide protection, which results in relatively normal behavior and much less severe pathology. Importantly, LDN/OSU-0215111 modulated disease directly as the delay in disease progression was sustained even after 1 month of treatment cessation. We have shown previously that this compound series has profound benefits for amyloid- $\beta$-related pathology in $\mathrm{APP}_{\text {Swe,Ind }}$ mice [38]. The combined results of these two efficacy studies, which represent the two most common pathologies associated with AD, strongly support LDN/OSU-0215111 as a promising clinical candidate for the treatment of AD.

The finding that the compound treatment reduced total pTau levels and insoluble forms of tau after a single dose is significant. It is known that simply turning off the MAPT*P301L transgene using DOX does not lead to a rapid reduction of aberrant tau [60]. GSK3 $\beta$ is differentially phosphorylated at Ser9 and Tyr216, where phosphorylation of the former inhibits the activity and of the latter maximizes the activity [61]. It is predicted that tau has approximately 85 potential phosphorylation sites and GSK3 $\beta$ can target many of these sites $[62,63]$. The MAPT*P301L mutation in tau itself is also known to promote phosphorylation, further perpetuating a hyperphosphorylated state [64]. LDN/ OSU-0215111 treatment significantly increases Ser9 phosphorylation of GSK3 $\beta$, thus inhibiting the catalytic activity of GSK3 $\beta$ (Fig. 6c). Furthermore, this inhibition was maintained for up to $24 \mathrm{~h}$ after treatment (Fig. 6d) overlaying the interval between treatments resulting in persistent inhibition of GSK3 $\beta$ activity during this study. This may be sufficient to markedly reduce the hyperphosphorylation of tau and its subsequent deposition; however, more detailed mechanistic studies will be necessary to confirm the role that compound-mediated GSK3 $\beta$ inhibition plays in the phosphorylation state of mutant tau and whether compound-mediated modulation of GSK3 $\beta$ activity alone facilitates reduced pTau. This is a novel aspect of the mechanism of action for pyridazine-based compounds. Pyridazine derivatives are known to activate protein kinase C [42], and certain isoforms of protein kinase $\mathrm{C}$ are known to target GSK3 $\beta$ to inhibit activity; however, many other kinases are known to modulate GSK3 $\beta$ activity as well [65-68]. We are continuing to characterize the precise compound mechanism of action that mediates this robust reduction in pTau and tau deposition.
Previous reports have indicated that EAAT2 is decreased in rTg4510 mice [46, 69]. However, when we assessed EAAT2 expression in $\mathrm{rTg} 4510$ mice, we found that EAAT2 was globally upregulated in the forebrain and the increased EAAT2 was properly localized to lipid raft microdomain of the plasma membrane (Fig. 2b and Additional file 1: Figure S1c, d). This indicates that rTg4510 mice express supraphysiological levels of functional EAAT2 rather than non-functional aggregates. We have surmised this discrepancy may be related to the treatment of DOX. Application of DOX to the rodent chow silences mutant tau transgene expression [45]. In previous studies, parental mice were treated with DOX during breeding and progeny continued DOX treatment until switching to regular chow at 2 months of age $[46,69]$. Decreased EAAT2 was then found at the age of 7.5 months. In our study, rTg4510 mice were never treated with DOX, therefore allowing for transgene expression throughout the lifespan. Perhaps developmental differences due to the timing of mutant tau exposure account for this discrepancy in EAAT2. When we treated adult rTg4510 mice with DOX for 3 weeks, EAAT2 protein levels were reduced in a correlated manner to tau (Additional file 1a, b), indicating that elevated EAAT2 expression may be a consequence of mutant tau expression. However, this explanation may be insufficient as EAAT2 $\times$ rTg4510 mice exhibit decreased EAAT2 but no change in total tau expression relative to rTg4510 littermates. We are further exploring this phenomenon.

Even though EAAT2 expression was not decreased in rTg4510, both transgenic overexpression of EAAT2 and LDN/OSU-0215111 treatment provided protection against many aspects of disease pathology (Fig. 1). However, LDN/ OSU-0215111 provided additional benefits in $\mathrm{rTg} 4510$ mice that could not be accounted for by EAAT2 expression modulation alone as these benefits were not observed after EAAT2 overexpression. Behaviorally, treatment with the compound additionally normalized agitation-like hyperactivity (Figs. 3a and 4a) and, similarly, reduced gliosis (Figs. 3g, 4i) and aberrant tau expression (Figs. 3g, 6a) in rTg4510 mice while transgenic EAAT2 overexpression did not improve these phenotypes. Furthermore, for pathologies modified by both EAAT2 overexpression and compound treatment, beneficial effects observed were more robust for compound-treated $\mathrm{rTg} 4510$ mice than for EAAT2 $\times$ rTg4510 mice. Therefore, several of the primary benefits observed in the present therapy study may be directly attributable to the modulation of EAAT2 expression; however, it is clear that other emergent properties related to the compound mechanism of action enhance efficacy. Further research will be undertaken to better understand the multifactorial functions of the compound mechanism of action that provides these benefits. 


\section{Conclusions}

By testing pyridazine analogs in multiple models of $\mathrm{AD}$, we have been able to assess the efficacy in relation to multiple different aspects of the disease with different etiologies including amyloid- $\beta$, aberrant tau, synaptic loss, and neurodegeneration which are major hallmarks of the disease. In conclusion, when intervention is given at the early symptomatic stage, LDN/OSU-0215111 significantly improves synaptic integrity, prevents progression of neurodegeneration, decreases mutant tau phosphorylation/deposition, and reduces neuroinflammation associated with tauopathy. This results in normalized cognition and behavior at moderate and severe stages in the rTg4510 mouse model of Alzheimer's disease. Therefore, pyridazine derivatives have the potential for the treatment of AD.

\section{Additional file}

Additional file 1: EAAT2 expression in rTg4510 mice is functional and properly localized. $(a, b)$ At two months old, mice were treated with or without doxycycline (DOX) for three weeks to suppress mutant-tau expression. (a) Western blot analysis of forebrain total lysates showed rTg4510 mice given DOX exhibit substantial, but incomplete, reductions in the expression of all forms of tau. (b) In a similar manner, EAAT2 protein expression is reduced (partially normalized) in rTg4510 mice given DOX. (c) Hippocampal extracellular biotinylation showed that increased EAAT2 in rTg4510 mice is properly localized to the membrane. (d) The lipid-raft microdomain (fractions 3-6), which represents the functional membrane domain of EAAT2, also exhibited increased EAAT2 expression in the $r \mathrm{Tg} 4510$ vehicle group suggesting increased functionality. Together, this suggests that increased EAAT2 in rTg4510 mice is functional and not the result of accumulation of non-functional, intracellular aggregates. (DOCX $415 \mathrm{~kb}$ )

\section{Abbreviations}

DG: Dentate gyrus; DOX: Doxycycline; EAAT2: Excitatory amino acid transporter 2; Flot1: Flotillin-1; GFAP: Glial fibrillary acidic protein; GSK3ß: Glycogen synthase kinase-3 beta; LTP: Long-term potentiation; NMDA: N-methyl-D-aspartate; NR2B: N-methyl-D-aspartate receptor 2B; NORT: Novel object recognition task; PAP: Perisynaptic astrocytic processes; PSD-95: Postsynaptic density 95; pTau: Phosphorylated tau; P3: Tris-buffered saline extractable, Sarkosyl-insoluble fraction; TCL: Total cell lysate

\section{Acknowledgements}

We acknowledge Dr. Peter Davies (Litwin Zucker Center for Alzheimer's Research, Long Island) for providing Tau-related primary antibodies.

\section{Authors' contributions}

JBF and CGL designed the experiments and wrote the manuscript. JBF conducted and analyzed the experiments. RL, XW, and NK contributed to the biochemical studies and animal studies. FZ and CCA contributed to the electrophysiological studies. LL, MWS, and $\mathrm{KJH}$ contributed to the compound design and synthesis. All authors read and approved the final manuscript.

\section{Funding}

This work was financially supported by NIA (U01 AG054444), the Alzheimer's Drug Discovery Foundation, the Edward N. \& Della L. Thome Memorial Foundation, and the Harrington Discovery Institute. Electrophysiology studies were conducted in The Ohio State University Neuroscience Center Core which is supported by NINDS Center Core Grant (P30 NS045758 and P30 NS104177).

\section{Availability of data and materials}

The datasets generated and/or analyzed during the current study are available from the corresponding author upon reasonable request.

\section{Ethics approval and consent to participate}

All experiments were approved by the Institutional Animal Care and Use Committee of The Ohio State University (protocol \# 2008A0159-R3) and followed the guidelines established by the National Institutes of Health Guide for the Care and Use of Laboratory Animals.

\section{Consent for publication}

All authors have consented to publication.

\section{Competing interests}

The authors declare that they have no competing interests.

\section{Author details}

${ }^{1}$ Department of Neuroscience, College of Medicine, The Ohio State University, Columbus, OH, USA. '2Department of Neurology, Brigham and Women's Hospital, Harvard Medical School, Cambridge, MA, USA

Received: 6 February 2019 Accepted: 15 August 2019

Published online: 23 August 2019

\section{References}

1. Xu J, Murphy SL, Kochanek KD, Bastian B, Arias E. Deaths: final data for 2016. Natl Vital Stat Rep. 2018;67:1-76.

2. Assoc As. 2018 Alzheimer's disease facts and figures. Alzheimers Dement. 2018;14:367-425.

3. Hogan DB. Long-term efficacy and toxicity of cholinesterase inhibitors in the treatment of Alzheimer disease. Can J Psychiatr. 2014;59:618-23.

4. Emre M, Mecocci P, Stender K. Pooled analyses on cognitive effects of memantine in patients with moderate to severe Alzheimer's disease. J Alzheimers Dis. 2008;14:193-9.

5. Areosa SA, Sherriff F, McShane R. Memantine for dementia. Cochrane Database Syst Rev. 2005;3:CD003154. https://doi.org/10.1002/14651858. CD003154.pub3.

6. Simic G, Babic Leko M, Wray S, Harrington C, Delalle I, Jovanov-Milosevic N, Bazadona D, Buee L, de Silva R, Di Giovanni G, et al. Tau protein hyperphosphorylation and aggregation in Alzheimer's disease and other tauopathies, and possible neuroprotective strategies. Biomolecules. 2016;6:6.

7. Barage SH, Sonawane KD. Amyloid cascade hypothesis: pathogenesis and therapeutic strategies in Alzheimer's disease. Neuropeptides. 2015;52:1-18.

8. Rudy CC, Hunsberger HC, Weitzner DS, Reed MN. The role of the tripartite glutamatergic synapse in the pathophysiology of Alzheimer's disease. Aging Dis. 2015:6:131-48.

9. Gold M. Phase II clinical trials of anti-amyloid beta antibodies: when is enough, enough? Alzheimers Dement (N Y). 2017;3:402-9.

10. Behl C. Amyloid in Alzheimer's disease: guilty beyond reasonable doubt? Trends Pharmacol Sci. 2017:38:849-51.

11. Mehta D, Jackson R, Paul G, Shi J, Sabbagh M. Why do trials for Alzheimer's disease drugs keep failing? A discontinued drug perspective for 2010-2015. Expert Opin Investig Drugs. 2017;26:735-9.

12. Medina M. An overview on the clinical development of tau-based therapeutics. Int J Mol Sci. 2018;19:1160.

13. Javidnia M, Kurd-Misto B, Moussa C. An update on clinical trials targeting human tauopathies. Clin Trials Degener Dis. 2017;2:66-76.

14. Braak $H$, Braak E. Evolution of neuronal changes in the course of Alzheimer's disease. J Neural Transm Suppl. 1998;53:127-40.

15. Francis PT. Glutamatergic systems in Alzheimer's disease. Int J Geriatr Psychiatry. 2003;18:S15-21.

16. Neary D, Snowden JS, Mann DM, Bowen DM, Sims NR, Northen B, Yates PO, Davison AN. Alzheimer's disease: a correlative study. J Neurol Neurosurg Psychiatry. 1986;49:229-37.

17. DeKosky ST, Scheff SW. Synapse loss in frontal cortex biopsies in Alzheimer's disease: correlation with cognitive severity. Ann Neurol. 1990;27:457-64.

18. Masliah E, Ellisman M, Carragher B, Mallory M, Young S, Hansen L, DeTeresa $\mathrm{R}$, Terry RD. Three-dimensional analysis of the relationship between synaptic pathology and neuropil threads in Alzheimer disease. J Neuropathol Exp Neurol. 1992;51:404-14.

19. Masliah E, Alford M, DeTeresa R, Mallory M, Hansen L. Deficient glutamate transport is associated with neurodegeneration in Alzheimer's disease. Ann Neurol. 1996:40:759-66. 
20. Kirvell SL, Esiri M, Francis PT. Down-regulation of vesicular glutamate transporters precedes cell loss and pathology in Alzheimer's disease. $J$ Neurochem. 2006;98:939-50.

21. Kashani A, Lepicard E, Poirel O, Videau C, David JP, Fallet-Bianco C, Simon A Delacourte A, Giros B, Epelbaum J, et al. Loss of VGLUT1 and VGLUT2 in the prefrontal cortex is correlated with cognitive decline in Alzheimer disease. Neurobiol Aging. 2008;29:1619-30.

22. Sokolow S, Luu SH, Nandy K, Miller CA, Vinters HV, Poon WW, Gylys KH. Preferential accumulation of amyloid-beta in presynaptic glutamatergic terminals (VGluT1 and VGluT2) in Alzheimer's disease cortex. Neurobiol Dis. 2012;45:381-7.

23. Filippini N, MacIntosh BJ, Hough MG, Goodwin GM, Frisoni GB, Smith SM, Matthews PM, Beckmann CF, Mackay CE. Distinct patterns of brain activity in young carriers of the APOE-epsilon4 allele. Proc Natl Acad Sci U S A. 2009:106:7209-14

24. Dennis NA, Browndyke JN, Stokes J, Need A, Burke JR, Welsh-Bohmer KA, Cabeza R. Temporal lobe functional activity and connectivity in young adult APOE varepsilon4 carriers. Alzheimers Dement. 2010;6:303-11.

25. Quiroz YT, Budson AE, Celone K, Ruiz A, Newmark R, Castrillon G, Lopera F, Stern CE. Hippocampal hyperactivation in presymptomatic familial Alzheimer's disease. Ann Neurol. 2010;68:865-75.

26. Dickerson BC, Salat DH, Greve DN, Chua EF, Rand-Giovannetti E, Rentz DM, Bertram L, Mullin K, Tanzi RE, Blacker D, et al. Increased hippocampal activation in mild cognitive impairment compared to normal aging and $A D$. Neurology. 2005;65:404-11.

27. Hamalainen A, Pihlajamaki M, Tanila H, Hanninen T, Niskanen E, Tervo S, Karjalainen PA, Vanninen RL, Soininen $H$. Increased $\mathrm{fMRI}$ responses during encoding in mild cognitive impairment. Neurobiol Aging. 2007; 28:1889-903.

28. Beagle AJ, Darwish SM, Ranasinghe KG, La AL, Karageorgiou E, Vossel KA. Relative incidence of seizures and myoclonus in Alzheimer's disease, dementia with Lewy bodies, and frontotemporal dementia. J Alzheimers Dis. 2017;60:211-23.

29. Rothstein JD, Martin L, Levey Al, Dykes-Hoberg M, Jin L, Wu D, Nash N, Kund RW. Localization of neuronal and glial glutamate transporters. Neuron. 1994:13:713-25

30. Rothstein JD, Dykes-Hoberg M, Pardo CA, Bristol LA, Jin L, Kuncl RW, Kanai Y, Hediger MA, Wang Y, Schielke JP, Welty DF. Knockout of glutamate transporters reveals a major role for astroglial transport in excitotoxicity and clearance of glutamate. Neuron. 1996;16:675-86.

31. Herman MA, Jahr CE. Extracellular glutamate concentration in hippocampal slice. J Neurosci. 2007;27:9736-41.

32. Bechtholt-Gompf AJ, Walther HV, Adams MA, Carlezon WA Jr, Ongur D, Cohen BM. Blockade of astrocytic glutamate uptake in rats induces signs of anhedonia and impaired spatial memory. Neuropsychopharmacology. 2010; 35:2049-59.

33. Pita-Almenar JD, Zou S, Colbert CM, Eskin A. Relationship between increase in astrocytic GLT-1 glutamate transport and late-LTP. Learn Mem. 2012;19: 615-26.

34. Heo S, Jung G, Beuk T, Hoger H, Lubec G. Hippocampal glutamate transporter 1 (GLT-1) complex levels are paralleling memory training in the multiple T-maze in C57BL/6J mice. Brain Struct Funct. 2012;217: 363-78.

35. Jacob CP, Koutsilieri E, Bartl J, Neuen-Jacob E, Arzberger T, Zander N, Ravid $R$, Roggendorf W, Riederer P, Grunblatt E. Alterations in expression of glutamatergic transporters and receptors in sporadic Alzheimer's disease. J Alzheimers Dis. 2007;11:97-116

36. Scott HA, Gebhardt FM, Mitrovic AD, Vandenberg RJ, Dodd PR. Glutamate transporter variants reduce glutamate uptake in Alzheimer's disease. Neurobiol Aging. 2011;32:553 e551-511.

37. Mookherjee P, Green PS, Watson GS, Marques MA, Tanaka K, Meeker KD, Meabon JS, Li N, Zhu P, Olson VG, Cook DG. GLT-1 loss accelerates cognitive deficit onset in an Alzheimer's disease animal model. J Alzheimers Dis. 2011:26:447-55.

38. Takahashi K, Kong Q, Lin Y, Stouffer N, Schulte DA, Lai L, Liu Q, Chang LC, Dominguez $S$, Xing $X$, et al. Restored glial glutamate transporter EAAT2 function as a potential therapeutic approach for Alzheimer's disease. J Exp Med. 2015;212:319-32

39. Lozovaya NA, Kopanitsa MV, Boychuk YA, Krishtal OA. Enhancement of glutamate release uncovers spillover-mediated transmission by N-methyl-Daspartate receptors in the rat hippocampus. Neuroscience. 1999;91:1321-30.
40. Tian G, Lai L, Guo H, Lin Y, Butchbach ME, Chang Y, Lin CL. Translational control of glial glutamate transporter EAAT2 expression. J Biol Chem. 2007; 282:1727-37.

41. Colton CK, Kong Q, Lai L, Zhu MX, Seyb Kl, Cuny GD, Xian J, Glicksman MA, Lin CL. Identification of translational activators of glial glutamate transporter EAAT2 through cell-based high-throughput screening: an approach to prevent excitotoxicity. J Biomol Screen. 2010;15:653-62.

42. Kong Q, Chang LC, Takahashi K, Liu Q, Schulte DA, Lai L, Ibabao B, Lin Y, Stouffer N, Das Mukhopadhyay C, et al. Small-molecule activator of glutamate transporter EAAT2 translation provides neuroprotection. J Clin Invest. 2014;124:1255-67.

43. Foster JB, Zhao F, Wang X, Xu Z, Lin K, Askwith CC, Hodgetts KJ, Lin CG. Pyridazine-derivatives enhance structural and functional plasticity of tripartite synapse via activation of local translation in astrocytic processes. Neuroscience. 2018;388:224-38.

44. Ramsden M, Kotilinek L, Forster C, Paulson J, McGowan E, SantaCruz K, Guimaraes A, Yue M, Lewis J, Carlson G, et al. Age-dependent neurofibrillary tangle formation, neuron loss, and memory impairment in a mouse model of human tauopathy (P301L). J Neurosci. 2005;25:10637-47.

45. Santacruz K, Lewis J, Spires T, Paulson J, Kotilinek L, Ingelsson M, Guimaraes A, DeTure M, Ramsden M, McGowan E, et al. Tau suppression in a neurodegenerative mouse model improves memory function. Science. 2005;309:476-81.

46. Hunsberger HC, Rudy CC, Batten SR, Gerhardt GA, Reed MN. P301L tau expression affects glutamate release and clearance in the hippocampal trisynaptic pathway. J Neurochem. 2015;132:169-82.

47. Cook C, Dunmore JH, Murray ME, Scheffel K, Shukoor N, Tong J, CastanedesCasey M, Phillips V, Rousseau L, Penuliar MS, et al. Severe amygdala dysfunction in a MAPT transgenic mouse model of frontotemporal dementia. Neurobiol Aging. 2014;35:1769-77.

48. Guo H, Lai L, Butchbach ME, Stockinger MP, Shan X, Bishop GA, Lin CL. Increased expression of the glial glutamate transporter EAAT2 modulates excitotoxicity and delays the onset but not the outcome of ALS in mice. Hum Mol Genet. 2003;12:2519-32.

49. Xing X, Chang LC, Kong Q, Colton CK, Lai L, Glicksman MA, Lin CL, Cuny GD. Structure-activity relationship study of pyridazine derivatives as glutamate transporter EAAT2 activators. Bioorg Med Chem Lett. 2011;21: 5774-7.

50. Blackmore T, Meftah S, Murray TK, Craig PJ, Blockeel A, Phillips K, Eastwood B, O'Neill MJ, Marston H, Ahmed Z, et al. Tracking progressive pathological and functional decline in the rTg4510 mouse model of tauopathy. Alzheimers Res Ther. 2017;9:77.

51. Li S, Jin M, Koeglsperger T, Shepardson NE, Shankar GM, Selkoe DJ. Soluble $A \beta$ oligomers inhibit long-term potentiation through a mechanism involving excessive activation of extrasynaptic NR2B-containing NMDA receptors. J Neurosci. 2011;31:6627-38.

52. Goebel-Goody SM, Davies KD, Alvestad Linger RM, Freund RK, Browning MD. Phospho-regulation of synaptic and extrasynaptic N-methyl-D-aspartate receptors in adult hippocampal slices. Neuroscience. 2009;158:1446-59.

53. Sahara N, DeTure M, Ren Y, Ebrahim AS, Kang D, Knight J, Volbracht C, Pedersen JT, Dickson DW, Yen SH, Lewis J. Characteristics of TBS-extractable hyperphosphorylated tau species: aggregation intermediates in rTg4510 mouse brain. J Alzheimers Dis. 2013;33:249-63.

54. Kong Q, Takahashi K, Schulte D, Stouffer N, Lin Y, Lin CL. Increased glial glutamate transporter EAAT2 expression reduces epileptogenic processes following pilocarpine-induced status epilepticus. Neurobiol Dis. 2012;47: 145-54.

55. Attar A, Liu T, Chan WT, Hayes J, Nejad M, Lei K, Bitan G. A shortened Barnes maze protocol reveals memory deficits at 4-months of age in the tripletransgenic mouse model of Alzheimer's disease. PLoS One. 2013;8:e80355.

56. Butchbach ME, Tian G, Guo H, Lin CL. Association of excitatory amino acid transporters, especially EAAT2, with cholesterol-rich lipid raft microdomains: importance for excitatory amino acid transporter localization and function. J Biol Chem. 2004;279:34388-96.

57. Tian G, Kong Q, Lai L, Ray-Chaudhury A, Lin CL. Increased expression of cholesterol 24S-hydroxylase results in disruption of glial glutamate transporter EAAT2 association with lipid rafts: a potential role in Alzheimer's disease. J Neurochem. 2010;113:978-89.

58. Stambolic V, Woodgett JR. Mitogen inactivation of glycogen synthase kinase-3 beta in intact cells via serine 9 phosphorylation. Biochem J. 1994; 303(Pt 3):701-4 
59. Llorens-Martin M, Jurado J, Hernandez F, Avila J. GSK-3beta, a pivotal kinase in Alzheimer disease. Front Mol Neurosci. 2014;7:46.

60. Spires TL, Orne JD, SantaCruz K, Pitstick R, Carlson GA, Ashe KH, Hyman BT. Region-specific dissociation of neuronal loss and neurofibrillary pathology in a mouse model of tauopathy. Am J Pathol. 2006;168:1598-607.

61. Beurel E, Grieco SF, Jope RS. Glycogen synthase kinase-3 (GSK3): regulation, actions, and diseases. Pharmacol Ther. 2015;148:114-31.

62. Noble W, Hanger DP, Miller CC, Lovestone S. The importance of tau phosphorylation for neurodegenerative diseases. Front Neurol. 2013;4:83.

63. Medina M, Garrido JJ, Wandosell FG. Modulation of GSK-3 as a therapeutic strategy on tau pathologies. Front Mol Neurosci. 2011;4:24.

64. Alonso Adel C, Mederlyova A, Novak M, Grundke-lqbal I, labal K. Promotion of hyperphosphorylation by frontotemporal dementia tau mutations. J Biol Chem. 2004;279:34873-81.

65. Kisoh K, Hayashi H, Itoh T, Asada M, Arai M, Yuan B, Tanonaka K, Takagi N. Involvement of GSK-3 $\beta$ phosphorylation through PI3-K/Akt in cerebral ischemia-induced neurogenesis in rats. Mol Neurobiol. 2017;54:7917-27.

66. Moore SF, van den Bosch MT, Hunter RW, Sakamoto K, Poole AW, Hers I. Dual regulation of glycogen synthase kinase 3 (GSK3)alpha/beta by protein kinase C (PKC)alpha and Akt promotes thrombin-mediated integrin alphallbbeta3 activation and granule secretion in platelets. J Biol Chem. 2013:288:3918-28.

67. Tsujio I, Tanaka T, Kudo T, Nishikawa T, Shinozaki K, Grundke-lqbal I, lqbal K, Takeda M. Inactivation of glycogen synthase kinase-3 by protein kinase C delta: implications for regulation of tau phosphorylation. FEBS Lett. 2000; 469:111-7.

68. Christian SL, Sims PV, Gold MR. The B cell antigen receptor regulates the transcriptional activator beta-catenin via protein kinase C-mediated inhibition of glycogen synthase kinase-3. J Immunol. 2002;169:758-69.

69. Hunsberger HC, Weitzner DS, Rudy CC, Hickman JE, Libell EM, Speer RR, Gerhardt GA, Reed MN. Riluzole rescues glutamate alterations, cognitive deficits, and tau pathology associated with P301L tau expression. J Neurochem. 2015:135:381-94.

\section{Publisher's Note}

Springer Nature remains neutral with regard to jurisdictional claims in published maps and institutional affiliations.

Ready to submit your research? Choose BMC and benefit from:

- fast, convenient online submission

- thorough peer review by experienced researchers in your field

- rapid publication on acceptance

- support for research data, including large and complex data types

- gold Open Access which fosters wider collaboration and increased citations

- maximum visibility for your research: over $100 \mathrm{M}$ website views per year

At $\mathrm{BMC}$, research is always in progress.

Learn more biomedcentral.com/submissions 